\title{
Polymeric carbon nitride coupled with a molecular thiomolybdate catalyst: exciton and charge dynamics in light-driven hydrogen evolution
}

Ashwene Rajagopal, ${ }^{a}$ Elham Akbarzadeh, ${ }^{a}$ Chunyu Li,${ }^{b, c}$ Dariusz Mitoraj, ${ }^{d}$ Igor Krivtsov, ${ }^{d, *}$

Christiane Adler, ${ }^{d}$ Thomas Diemant,${ }^{e}$ Johannes Biskupek, ${ }^{f}$ Ute Kaiser, ${ }^{f}$ Changbin $\operatorname{Im},{ }^{d}$ Magdalena

Heiland, ${ }^{a}$ Timo Jacob, ${ }^{d, g, h}$ Carsten Streb,${ }^{a, g, h} *$ Benjamin Dietzek,${ }^{b, c, i} *$ Radim Beranek ${ }^{d, *}$

a Institute of Inorganic Chemistry I, Ulm University, Albert-Einstein-Allee 11, 89081 Ulm, Germany

$b \quad$ Institute of Physical Chemistry and Abbe Center of Photonics, Friedrich Schiller University Jena, Lessingstr. 10, 07743 Jena, Germany

c Department Functional Interfaces, Leibniz Institute of Photonic Technology (IPHT), Albert-Einstein-Str. 9, 07745 Jena, Germany

d Institute of Electrochemistry, Ulm University, Albert-Einstein-Allee 47, 89081 Ulm, Germany

e Institute of Surface Chemistry and Catalysis, Ulm University, Albert-Einstein-Allee 47, 89081 Ulm, Germany

f Electron Microscopy of Materials Science, Central Facility for Electron Microscopy, Ulm University, AlbertEinstein-Allee 11, 89081, Ulm, Germany

g Helmholtz-Institute-Ulm (HIU), Helmholtzstr. 11, 89081, Ulm, Germany

$h \quad$ Karlsruhe Institute of Technology (KIT), P.O. Box 3640, 76021, Karlsruhe, German

i Center for Energy and Environmental Chemistry Jena (CEEC Jena), Philosophenweg 7a, 07743 Jena, Germany

*Corresponding authors: igor.krivtsov@uni-ulm.de, carsten.streb@uni-ulm.de, benjamin.dietzek@uni-jena.de, radim.beranek@uni-ulm.de 


\begin{abstract}
Solar hydrogen evolution from water is a necessary step to overcome the challenges of rising energy demand and associated environmental concerns. Low-cost photocatalytic architectures based on polymeric light absorbers coupled to highly efficient molecular catalysts might represent an attractive platform to address this issue. However, to-date, our mechanistic knowledge of these systems is still largely underdeveloped. In this study, a molecular molybdenum sulfide hydrogen evolving catalyst, $\left[\mathrm{Mo}_{3} \mathrm{~S}_{13}\right]^{2-}$, is loaded onto polymeric carbon nitride $\left(\mathrm{CN}_{x}\right)$ photoabsorber by impregnation. The resulting composite shows enhanced photocatalytic activity for hydrogen evolution compared to pristine $\mathrm{CN}_{x}$ under monochromatic visible light $(\lambda=420 \mathrm{~nm})$ irradiation in the presence of sacrificial reducing agents. The light-driven dynamics of excitons and charges involved in hydrogen evolution catalysis were studied by a combination of spectroscopic (steady-state and time-resolved photoluminescence, femtosecond time-resolved transient absorption) and photoelectrochemical (open-circuit photopotential transients) methods. We demonstrate that the molecular molybdenum sulfide catalyst, at optimum loading (10 wt\% nominal), improves the charge separation in the $\mathrm{CN}_{x}$ absorber by facilitating the depopulation of emissive (band-edge) or non-emissive (shallow trap) states, followed by an effectively catalyzed transfer of electrons from the charge-separated state (deep trap) to protons in the solution. The results provide important insights into the complex interplay between polymeric light absorbers and molecular redox catalysts, indicating that the electron transfer to the catalyst occurs on relatively longer (nanosecond - seconds) time scale, as the catalyst had no impact on the ultrafast (sub-nanosecond) photoinduced kinetics in the $\mathrm{CN}_{\mathrm{x}}$. These findings are of crucial importance for further development of soft-matter based architectures for solar fuels production.
\end{abstract}




\section{Introduction}

Sunlight-driven photocatalytic hydrogen evolution reaction (HER) remains one of the greatest challenges on the way towards sustainable alternatives to fossil fuels. ${ }^{1}$ A vast range of materials and approaches intended to tackle this goal have been investigated, and the pertinent research results have now been summarized in numerous review papers. ${ }^{2-5}$ The challenge is far from trivial: in order to be implemented in real life, the photocatalyst must be highly active, selective and stable, and at the same time based on low-cost and abundant elements. Hence, there is a quest for replacing conventional, mostly metal oxide-based semiconductors and noble metal co-catalysts with more affordable alternatives. ${ }^{6}$ In 2009, X. Wang et al. stirred the research community with the discovery of photocatalytic properties of polymeric carbon nitride (also referred in literature as melon, $\mathrm{CN}_{x}, \mathrm{C}_{3} \mathrm{~N}_{4}$ polymer, or $\left.g-\mathrm{C}_{3} \mathrm{~N}_{4}\right){ }^{7}$ This finding gave rise to a large number of publications on carbon nitride polymers modified with various co-catalysts, such as Pt and other noble metals, ${ }^{8-10}$ metal-organic complexes, ${ }^{11}$ metal phosphides, ${ }^{12}$ and metal sulphides. ${ }^{13}$ The latter received a special attention as $\mathrm{WS}_{2}{ }^{14}$ or $\mathrm{MoS}_{2}{ }^{15}$ were demonstrated to be efficient alternatives to the benchmark Pt catalysts for HER. However, in such layered metal sulfides only the undercoordinated edge sulfur atoms act as active sites for hydrogen evolution, while the rest of their $2 \mathrm{D}$ structure is inert. ${ }^{16}$ This finding prompted the search for molecular ${ }^{17}$ or nanoparticulate forms ${ }^{18}$ of these materials, with the aim to maximize the number of exposed active species. The $\left[\mathrm{Mo}_{3} \mathrm{~S}_{13}\right]^{2-}$ molecular clusters have been established as one of such promising co-catalysts for dark electrocatalytic ${ }^{16,19-22}$ and photocatalytic HER under heterogeneous ${ }^{23-25}$ and homogeneous conditions. ${ }^{26,27}$ Anchoring of the cluster onto various solid catalyst supports or light absorbers is straightforward and has been demonstrated for $\mathrm{TiO}_{2},{ }^{28}$ carbon materials, ${ }^{20,21}$ and recently also for polymeric carbon nitride-based material. ${ }^{25}$ More specifically, X. Wang et al. have coupled $\left[\mathrm{Mo}_{3} \mathrm{~S}_{13}\right]^{2-}\left[=\left\{\mathrm{Mo}_{3}\right\}\right]$ to protonated mesoporous carbon nitride with rod-like morphology (diameter ca. $1 \mu \mathrm{m}$ ), and the activity in photocatalytic HER of the hybrid was reported to be comparable with that of Pt-modified mesoporous carbon nitride using lactic acid as sacrificial electron donor. ${ }^{25}$ However, to the best of our knowledge, no insight into the 
interaction and charge transfer processes between the support and co-catalyst has been presented so far. Herein, we demonstrate that $\left\{\mathrm{Mo}_{3}\right\}$ deposited onto conventional polymeric carbon nitride can effectively catalyse visible light-driven hydrogen evolution using methanol as a reducing agent. Furthermore, using a combination of spectroscopic (steady-state and time-resolved photoluminescence, transient absorption) and photoelectrochemical (open-circuit photopotential) tools we shed light on the complex interplay between the carbon nitride light absorber and the molecular $\left\{\mathrm{Mo}_{3}\right\}$ catalyst influencing the exciton dynamics and the kinetics of catalytic turnover in light-driven hydrogen evolution.

\section{Experimental}

\subsection{Materials}

Melamine, hexachloroplatinic acid hydrate $\left(\mathrm{H}_{2} \mathrm{PtCl}_{6} \mathrm{nH}_{2} \mathrm{O}\right)$, triethanolamine (TEOA) were purchased from Aldrich, methanol was supplied by VWR chemicals. $\left(\mathrm{NH}_{4}\right)_{6}\left[\mathrm{Mo}_{7} \mathrm{O}_{24}\right] \times 4 \mathrm{H}_{2} \mathrm{O}$ and methanol for catalysis was purchased from Aldrich. Ammonium polysulfide was purchased from Chemos GmbH.

\subsection{Synthesis}

Synthesis of polymeric carbon nitride: The polymeric carbon nitride $\left(\mathrm{CN}_{\mathrm{x}}\right)$ was prepared by thermal polycondensation of $30 \mathrm{~g}$ melamine at $530^{\circ} \mathrm{C}$ for $4 \mathrm{~h}$ in a lid-covered crucible.

Synthesis of $\left(\mathbf{N H}_{4}\right)_{2}\left[\mathrm{Mos}_{3} \mathrm{~S}_{13}\right] \times \mathbf{2 H}_{2} \mathrm{O}$ : The thiomolybdate $\left(\mathrm{NH}_{4}\right)_{2}\left[\mathrm{Mo}_{3} \mathrm{~S}_{13}\right] \times 2 \mathrm{H}_{2} \mathrm{O}$ was prepared by a modification of the synthesis reported by Müller et al. ${ }^{29}\left(\mathrm{NH}_{4}\right)_{6}\left[\mathrm{Mo} 7 \mathrm{O}_{24}\right] \times 4 \mathrm{H}_{2} \mathrm{O}(4.0 \mathrm{~g}, 3.2 \mathrm{mmol})$ was dissolved in water $(20 \mathrm{ml})$ in a round bottom flask, then ammonium polysulfide $\left(\left(\mathrm{NH}_{4}\right)_{2} \mathrm{~S}_{\mathrm{x}}\right)$ solution (120 ml, 25 wt.-\%) was added to it and fitted with condenser. The solution was heated to 96 ${ }^{\circ} \mathrm{C}$ for five days with slow stirring. Dark-red crystals of $\left(\mathrm{NH}_{4}\right)_{2}\left[\mathrm{Mo}_{3} \mathrm{~S}_{13}\right] \times 2 \mathrm{H}_{2} \mathrm{O}$ formed and were removed by filtration, washed with water, ethanol, carbon disulfide and ether. Finally, the product was air-dried. Yield: $5.6 \mathrm{~g}$ (7.16 mmol, $97.9 \%$ based on Mo). 
Synthesis of $\mathrm{Na}_{2}\left[\mathrm{Mo}_{3} \mathrm{~S}_{13}\right] \times \mathbf{5 H}_{2} \mathrm{O}: \mathrm{Na}_{2}\left[\mathrm{Mo}_{3} \mathrm{~S}_{13}\right]$ x $5 \mathrm{H}_{2} \mathrm{O}$ was synthesized as follows. $\left(\mathrm{NH}_{4}\right)_{2}\left[\mathrm{Mo}_{3} \mathrm{~S}_{13}\right] \times 2 \mathrm{H}_{2} \mathrm{O}(3.02 \mathrm{~g}, 3.86 \mathrm{mmol})$ was suspended in an aqueous $\mathrm{NaOH}$ solution $(1 \mathrm{wt} .-\%$, $40 \mathrm{ml}$ ) and stirred under reduced pressure $(20 \mathrm{mbar})$ for $2 \mathrm{~h}$, in order to remove ammonium as $\mathrm{NH}_{3}$ gas. The resulting dark red solution was filtered into an aqueous $\mathrm{NaCl}$ solution (10 wt.-\%, $100 \mathrm{ml})$. After $12 \mathrm{~h}$, the precipitated product was isolated by filtration, washed with 2-propanol and diethyl ether, and dried in vacuo at room temperature to give red-brown powder of $\mathrm{Na}_{2}\left[\mathrm{Mo}_{3} \mathrm{~S}_{13}\right] \times 5 \mathrm{H}_{2} \mathrm{O}$. Yield: $3.20 \mathrm{~g}$ (3.78 mmol, $95.9 \%$ based on Mo).

\section{Synthesis of $\mathrm{CN}_{\mathbf{x}}-\{\mathrm{Moz}\}$ composites:}

$\mathrm{CN}_{\mathrm{x}^{-}}\left\{\mathrm{Mo}_{3}\right\}$ hybrids were synthesized through a two-step deposition process at room temperature. In a typical procedure, $20 \mathrm{mg}$ of as-prepared $\mathrm{CN}_{\mathrm{x}}$ was dispersed in $20 \mathrm{~mL}$ of methanol by ultrasonication for $3 \mathrm{~h}$ to prepare a homogenous suspension. Then, a measured amount of $\mathrm{Na}_{2}\left[\mathrm{Mo}_{3} \mathrm{~S}_{13}\right]$ (soluble in methanol) was added to it and stirred for $24 \mathrm{~h}$. The solid was collected by centrifugation and three times washed with methanol to remove the excess of $\left\{\mathrm{Mo}_{3}\right\}$. Finally, the obtained precipitates were air-dried at room temperature under ambient conditions giving $\mathrm{CN}_{\mathrm{x}^{-}}\left\{\mathrm{Mo}_{3}\right\}$. Different loadings of $\left\{\mathrm{Mo}_{3}\right\}$ were deposited onto the $\mathrm{CN}_{\mathrm{x}}$ material.

Synthesis of Pt-modified $\mathbf{C N}_{\mathbf{x}}$ : The platinized $\mathrm{CN}_{\mathrm{x}}\left(\mathrm{CN}_{\mathrm{x}}-\mathrm{Pt}\right)$ was prepared as a benchmark photocatalyst using a photodeposition method. For this, the $\mathrm{CN}_{\mathrm{x}}$ powder $(0.2 \mathrm{~g})$ was suspended in 20 $\mathrm{mL} \mathrm{H}_{2} \mathrm{O}: \mathrm{MeOH}(9: 1, \mathrm{v}: \mathrm{v})$ solution containing hexachloroplatinic acid (4 mg), ultrasonicated for 1h, bubbled with argon gas and irradiated for 30 min with a 150W Xe-lamp equipped with a KG3 (Schott) heat filter. Subsequently, the powder was washed by centrifugation and dried overnight at $60{ }^{\circ} \mathrm{C}$.

\subsection{Characterization}

ICP-AES. The actual loading of molybdenum sulfide cluster in the samples was determined using an inductively coupled plasma atomic emission spectrometer (ICP-AES, Horiba Jobin Yvon). For this, the $\mathrm{Mo}-\mathrm{CN}_{\mathrm{x}}-\left\{\mathrm{Mo}_{3}\right\}$ samples were dissolved in $1 \mathrm{M} \mathrm{KOH}$ at $100{ }^{\circ} \mathrm{C}$ in autoclave.

FT-IR spectroscopy: FT-IR spectroscopy was performed on a Shimadzu FT-IR-8400S spectrometer. Samples were prepared as $\mathrm{KBr}$ pellets. 
X-ray powder diffraction (XRD): XRD was collected on a Rigaku XRD-6000 diffractometer using $\mathrm{Cu} \mathrm{K} \alpha$ radiation $(\lambda=0.154 \mathrm{~nm})$.

Thermogravimetric analysis (TGA): TGA was performed on a Setaram Setsys CS Evo (30 $1000^{\circ} \mathrm{C}$ at $10 \mathrm{~K} / \mathrm{min}, 50 \mathrm{ml} / \mathrm{min}$ air, Graphite crucible $0.5 \mathrm{ml}$ ).

X-ray photoelectron spectroscopy (XPS): XPS measurements were performed with a PHI 5800 MultiTechnique ESCA system using monochromatized Al $\mathrm{K} \alpha$ radiation $(250 \mathrm{~W}, 15 \mathrm{kV})$ and pass energies of 93.9 and $29.35 \mathrm{eV}$ for survey and detail spectra, respectively, at a detection angle of $45^{\circ}$. The measurements were analyzed with the CasaXPS software, using a Shirley-type background and peaks of Gaussian-Lorentzian peak shape (70\% G / 30\% L).

Transmission Electron Microscopy (TEM): The samples were dispersed in ethanol (supersonic bath) and drop-cast on holey carbon TEM grids. The TEM investigations were carried out using an image-side corrected FEI Titan 80-300 microscope operating at $80 \mathrm{kV}$. Imaging included diffraction pattern from selected areas and high resolution (HR) TEM. Energy filtered imaging exploiting absorption edges for elemental mapping were acquired using a Gatan GIF Quantum energy filter attached to microscope.

Diffuse reflectance spectroscopy (DRS): Diffuse reflectance UV-vis spectra of solids were recorded using a Shimadzu UV2600 UV-vis spectrophotometer from the samples pressed in pellets with $\mathrm{BaSO}_{4}$.

Spectroscopic characterization: Polymeric carbon nitride suspensions for spectroscopic study were prepared by sonicating the carbon nitrides in deionized water $\left(2 \mathrm{mg} \mathrm{mL}^{-1}\right)$ for $15 \mathrm{~min}$. The supernatant liquid was collected after centrifugation (10 min, $7500 \mathrm{rpm}$ ) and used for steady-state emission and fs-transient absorption spectroscopy.

Steady-state emission spectra $\left(\lambda_{\mathrm{ex}}=380 \mathrm{~nm}\right)$ were recorded with a FLS980 spectrometer (Edinburgh Instruments) in a $1 \mathrm{~cm}$ quartz cell. Time resolved emission data were recorded using a Hamamatsu HPDTA streak camera. A Ti:sapphire laser (Tsunami, Newport Spectra-Physics GmbH) was used as the light source and a pulse selector (model 3980, Newport Spectra-Physics GmbH) was used to 
reduce the repetition rate of the pulse train to $400 \mathrm{kHz}$. The emission was collected from a $1 \mathrm{~cm}$ cuvette in a $90^{\circ}$ angle between the pump beam and a CHROMEX spectrograph detector. Analysis of the time-resolved emission data was performed using DecayFit software. Femtosecond (fs) transient absorption spectra were collected by using a previously reported home-built pump-probe laser system $^{30}$ based on an amplified Ti:Sapphire oscillator (Libra, Coherent Inc.). The pump pulses centered at $325 \mathrm{~nm}$ were generated in a collinear optical-parametric amplifier (TOPAS-C, LightConversion Ltd.). The power of the pump beam was kept at $0.15 \mathrm{~mW}$ before samples. The white light continuum between 450 and $785 \mathrm{~nm}$ used to probe the photoexcited sample is generated by focusing a part of the fundamental laser output into an eccentrically rotating $\mathrm{CaF}_{2}$ plate. The resultant supercontinuum is delayed in time with respect to the pump beam by means of an optical delay line and the polarization between probe and pump is set at the magic angle. The data were collected from the suspensions in $1 \mathrm{~cm}$ cuvettes.

Photopotential measurements: $50 \mathrm{mg}$ of photocatalyst were suspended in $250 \mu \mathrm{L}$ of methanol and sonicated for 5 minutes. Then, $200 \mu \mathrm{L}$ of the suspension was smeared onto an FTO glass by doctor blading using a scotch tape as frame and spacer. The photoelectrodes were dried at $100{ }^{\circ} \mathrm{C}$ for 15 minutes and pressed for 3 minutes at a pressure of $200 \mathrm{~kg} \mathrm{~cm}^{-2}$. The photoelectrochemical setup consisted of a SP-300 BioLogic potentiostat and a three-electrode configuration using a platinum counter electrode and a $\mathrm{Ag} / \mathrm{AgCl}(3 \mathrm{M} \mathrm{KCl})$ reference electrode. The photoelectrodes were pressed against an O-ring of the cell leaving an irradiated area of $0.5 \mathrm{~cm}^{2}$. The measurements were collected under open circuit voltage conditions. The photoelectrodes were irradiated from the backside (through the FTO glass) by monochromatic light of $380 \mathrm{~nm}$ (Instytut Fotonowy). The measurements were conducted in a pH 7 lithium perchlorate electrolyte under argon atmosphere (solution was bubbled with Ar for 30 minutes) in the absence of any sacrificial electron donor.

\subsection{Photocatalytic studies}

The preliminary photocatalytic experiments showed that the nominal mass ratio of $1: 10\left(\left\{\mathrm{Mo}_{3}\right\}: \mathrm{CN}_{\mathrm{x}}\right)$ was optimal for photocatalytic activity (see Electronic Supplementary Information, ESI, Fig. S1), 
hence the detailed study of the photocatalytic properties was focused on this material in the following. The photocatalytic hydrogen evolution experiments were carried out using a custom-built air-cooling apparatus for maintaining room temperature $\left(22^{\circ} \mathrm{C}\right)$ and constant irradiation of the sample. Experiments were carried out in $21 \mathrm{~mL}$ Schlenk tubes capped with rubber septa. $10 \mathrm{mg}$ of the $\mathrm{CN}_{\mathrm{x}^{-}}$ based catalysts were added to the Schlenk tube equipped with magnetic stirrer. The tube was evacuated and filled with argon. $\mathrm{A}_{2} \mathrm{O}: \mathrm{MeOH}(9: 1$, v/v) solution, with or without addition of additional sacrificial electron donor, was purged with argon. $10 \mathrm{~mL}$ of the degassed solution were added to the photocatalyst in the Schlenk tube under inert conditions and kept under constant irradiation from a LED source $\left(\lambda=420 \mathrm{~nm}\right.$; ca. $\left.50 \mathrm{~mW} \mathrm{~cm}{ }^{-2}\right)$ in air-cooled photoreactors. The gas phase of the Schlenk tube was probed by inserting a gas-tight GC syringe through the septum and the amount of hydrogen in the gas phase was quantified using headspace gas chromatography.

Gas Chromatography: Gas-chromatography (GC) was performed on a Bruker Scion GC/MS, with a thermal conductivity detector 15 (column: molecular sieve $5 \mathrm{~A} 75 \mathrm{~m} \times 0.53 \mathrm{~mm}$, oven temperature $70{ }^{\circ} \mathrm{C}$, flow rate $25 \mathrm{ml} \mathrm{min}{ }^{-1}$, detector temperature $200{ }^{\circ} \mathrm{C}$ with Argon as carrier gas. The GC was calibrated by direct injection of known amounts of $\mathrm{H}_{2}$ gas.

\section{Results and discussion}

$\mathrm{X}$. Wang et al. demonstrated that the interaction between the negatively charged $\left[\mathrm{Mo}_{3} \mathrm{~S}_{13}\right]^{2-}\left[=\left\{\mathrm{Mo}_{3}\right\}\right]$ clusters and the polymeric carbon nitride surface can be reinforced by protonation of the latter, thus providing stronger electrostatic interaction. ${ }^{25}$ However, it was shown that $\left\{\mathrm{Mo}_{3}\right\}$ is also efficiently immobilized on negatively charged carbon surfaces, bearing $-\mathrm{OH}$ and $-\mathrm{COOH}$ functional groups. ${ }^{16}$ Polymeric carbon nitride (PCN), apart from its polyheptazine structure, also possesses various functional amino-groups that have positive charges and can play an important role as anchoring sites via electrostatic interactions and hydrogen bonding. ${ }^{31,32}$ One can therefore expect that $\left\{\mathrm{Mo}_{3}\right\}$ would selectively attach to these surface moieties without covering the entire polymeric carbon nitride surface. According to ICP data, the actual loadings of the $\mathrm{Na}_{2}\left[\mathrm{Mo}_{3} \mathrm{~S}_{13}\right] 5 \mathrm{H}_{2} \mathrm{O}$ clusters in the $\mathrm{CN}_{\mathrm{x}}$ 
samples are $0.24,0.85$ and $2.06 \mathrm{wt} \%$ for the nominal loadings of 2, 10 and $20 \mathrm{wt} \%$, respectively. The deposition of the $\left\{\mathrm{Mo}_{3}\right\}$ clusters onto carbon nitride does not affect the support's long-range order as only a slight reduction of the intensity of the characteristic (100) and (002) maxima is observed in the composite's XRD pattern with respect to the pristine $\mathrm{CN}_{\mathrm{x}}$, which is, most likely, related to its partial exfoliation under sonication (Fig. 1a). FTIR spectra corroborate the absence of significant structural changes in $\mathrm{CN}_{\mathrm{x}}$ caused by the co-catalyst incorporation (Fig. 1b; see also a detailed discussion in ESI). However, we note the reduction of the relative intensity of the peak around $3125 \mathrm{~cm}^{-1}$ in the spectrum of $\mathrm{CN}_{\mathrm{x}^{-}}\left\{\mathrm{Mo}_{3}\right\}$ (Fig. 1b). This can be assigned either to partial elimination of the uncondensed $\mathrm{NH}_{\mathrm{x}}$-groups caused by ultrasonication treatment or to their interaction with the $\left\{\mathrm{Mo}_{3}\right\}$ clusters. Only a small fraction of the $\left[\mathrm{Mo}_{3} \mathrm{~S}_{13}\right]^{2-}$ species present in the initial solution is retained on the $\mathrm{CN}_{\mathrm{x}}$ surface after washing. XPS surface elemental analysis of the $\mathrm{CN}_{\mathrm{x}}-\left\{\mathrm{Mo}_{3}\right\}$ sample (10 wt $\%$ loading) allows to estimate that the Mo: $\mathrm{N}$ atomic ratio in the sample is only about 0.03 , which implies that there is approximately one $\left\{\mathrm{Mo}_{3}\right\}$ cluster for every 13 heptazine units. XPS analysis confirms that the polymeric carbon nitride structure has not suffered significant structural changes upon $\left\{\mathrm{Mo}_{3}\right\}$ deposition. The C 1s spectrum displays two peaks located at $288.3 \mathrm{eV}$ and $284.8 \mathrm{eV}$ (ESI, Fig. S2). The peak with binding energy of $288.3 \mathrm{eV}$ is assigned to the typical aromatic $\mathrm{C}-\mathrm{N}=\mathrm{C}$ species in the triazine rings of the $\mathrm{CN}_{\mathrm{x}}$ framework and the peak at $284.8 \mathrm{eV}$ can be attributed to adventitious carbon (Fig. S2). In the N 1s spectra of the composite three peaks located at 398.7, 399.6 and $401.1 \mathrm{eV}$ can be ascribed to the $\mathrm{C}-\mathrm{N}=\mathrm{C}, \mathrm{N}-\mathrm{C}_{3}$ and $\mathrm{C}-\mathrm{NH}_{\mathrm{x}}$ groups, respectively (Fig. S2). ${ }^{32}$ As to the anchored $\left\{\mathrm{Mo}_{3}\right\}$, the presence of Mo in the hybrid becomes evident by analysis of the spectra in the Mo $3 \mathrm{~d}$ range. Apart of the $\mathrm{S} 2 \mathrm{~s}$ peak at $226.7 \mathrm{eV}$, which also appears in this energy range, two Mo $3 \mathrm{~d}$ peak doublets are detected. The first one with dominating intensity at 229.1 and $232.2 \mathrm{eV}$ can be attributed to $\mathrm{Mo}^{4+}$ and is most probably related to the $\left\{\mathrm{Mo}_{3}\right\}$ particles (Fig. 1c). ${ }^{33}$ The second doublet at 232.2 and $235.3 \mathrm{eV}$ is most likely due to traces of $\mathrm{Mo}^{6+}$ formed upon partial exchange of $\mathrm{S}_{2}{ }^{2-}$ by hydroxide or water ligands. The $S 2 p$ spectrum is more informative, since it confirms the integrity of the immobilized $\left\{\mathrm{Mo}_{3}\right\}$ clusters. The $\mathrm{S} 2 \mathrm{p}$ spectrum can be fitted by introducing two doublet peaks $\left(2 \mathrm{p}_{3 / 2}\right.$ 
and $\left.2 \mathrm{p}_{1 / 2}\right)$. The doublet at $(161.9 \mathrm{eV}$ and $163.1 \mathrm{eV})$ is attributed to the terminal $\mathrm{S}_{2}{ }^{2-}$ ligands and the doublet at $(163.1 \mathrm{eV}$ and $164.3 \mathrm{eV})$ is assigned to the apical $\mathrm{S}^{2-}$ and bridging $\mathrm{S}_{2}{ }^{2-}$ in the $\left[\mathrm{Mo}_{3} \mathrm{~S}_{13}\right]^{2-}$ clusters (Fig. 1d). ${ }^{16,33}$ Finally, the presence of sulfate species in the composite is indicated by another peak doublet at higher binding energy (168.1 and $169.3 \mathrm{eV})$, characteristic for $\mathrm{S}-\mathrm{O}$ binding. We assume that the sulfate was generated during the cation exchange process from residual sulfur existing in $\left(\mathrm{NH}_{4}\right)_{2} \mathrm{Mo}_{3} \mathrm{~S}_{13} \cdot 2 \mathrm{H}_{2} \mathrm{O}$ (Fig. 1d).
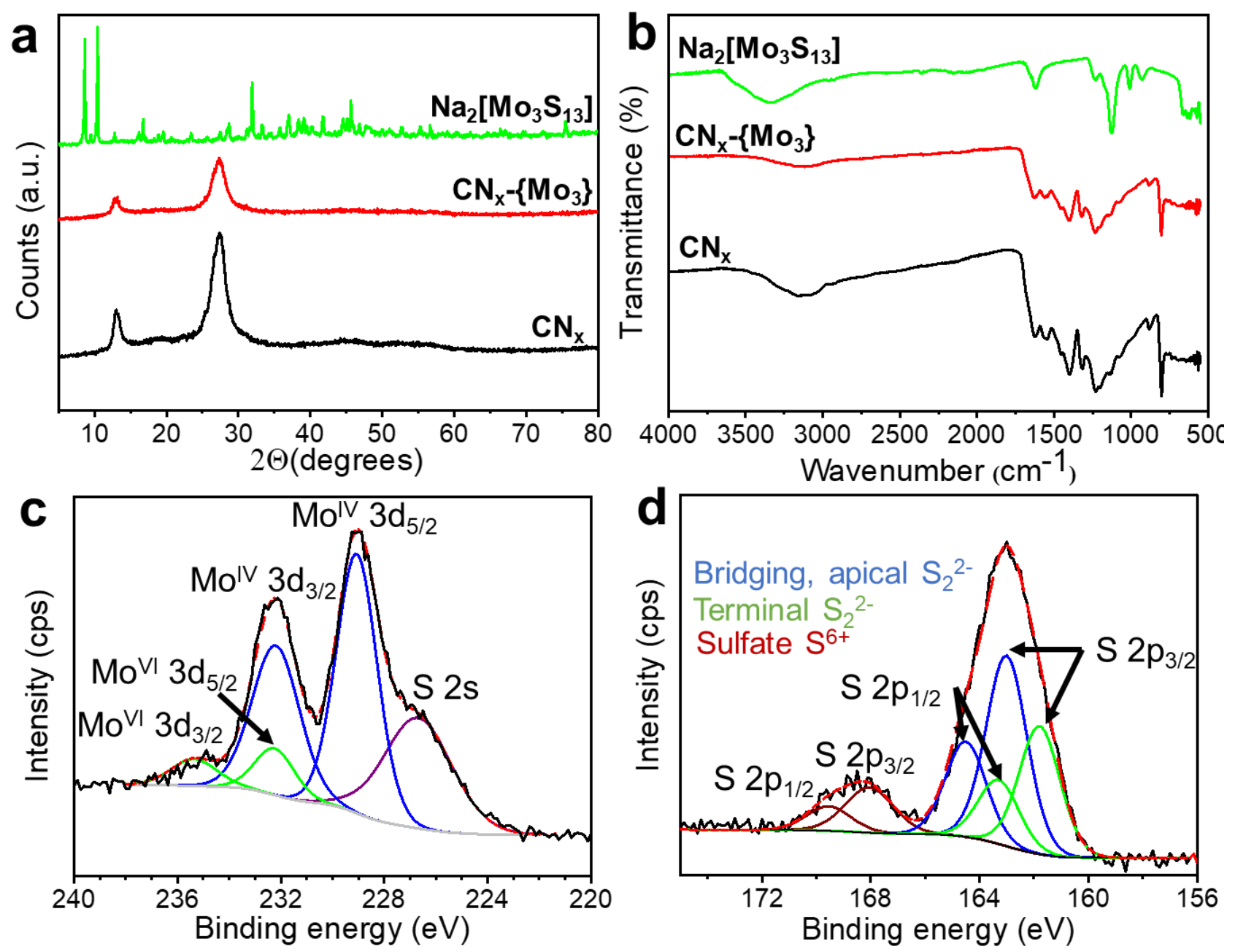

Figure 1. Characterization of materials: (a) XRD patterns; (b) FTIR spectra. Deconvoluted XP spectra in the Mo 3d (c) and $\mathrm{S} 2 \mathrm{p}(\mathrm{d})$ range of $\mathrm{CN}_{\mathrm{x}}-\left\{\mathrm{Mo}_{3}\right\}$ (10 wt\% loading) photocatalyst.

Figure 2 shows the results of the TEM investigation of $\mathrm{CN}_{x}-\left\{\mathrm{Mo}_{3}\right\}$. The overview images depict mostly large pieces of amorphous and undefined structure (Fig. 2a), however, crystalline flakes are also detectable in TEM (Fig. 2b). Energy filtered TEM images show a homogeneous distribution of 
Mo on the surface of the $\mathrm{CN}_{\mathrm{x}}$ material (Fig. 2a). It should be mentioned that the crystalline flakes were amorphized as result of electron irradiation when acquiring elemental maps (Fig. 2c). The diffraction pattern and FFT (fast fourier transform) of the crystalline flakes show first order reflection at $2.2 \mathrm{~nm}^{-1}$, which can be attributed to a polymeric carbon nitride phase (Fig. $2 \mathrm{~b}$ insets). Elemental mapping performed on the amorphous and crystalline parts of the sample shows uniform distribution of the $\left\{\mathrm{Mo}_{3}\right\}$ clusters in $\mathrm{CN}_{\mathrm{x}}$ material. We note that $\left\{\mathrm{Mo}_{3}\right\}$ deposition leads to a reduction of the specific surface area from 13 down to $5 \mathrm{~m}^{2} \mathrm{~g}^{-1}$.
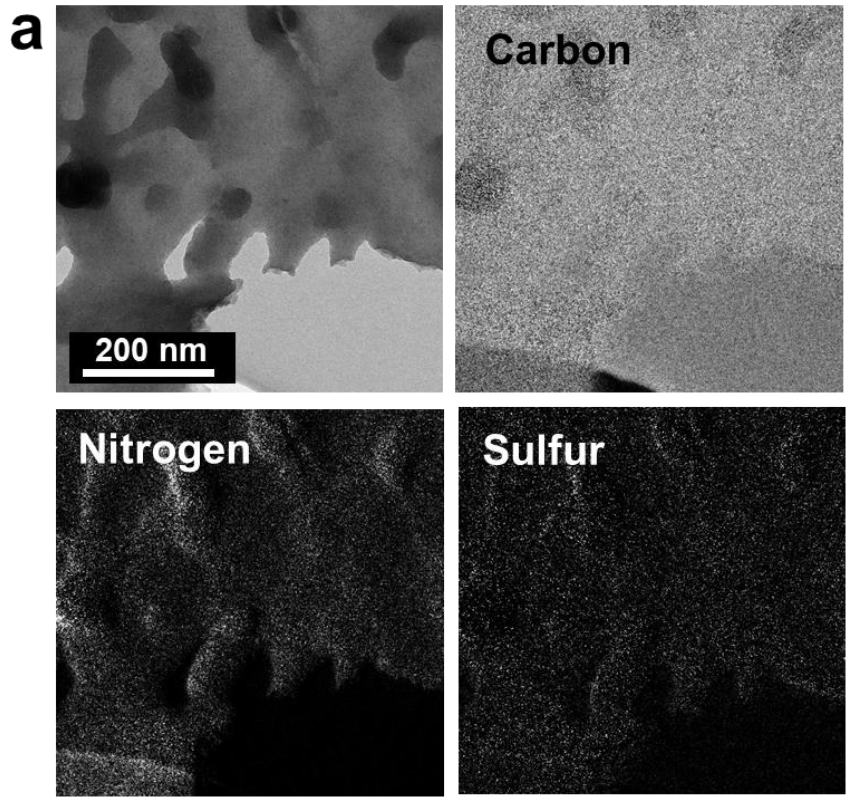

C
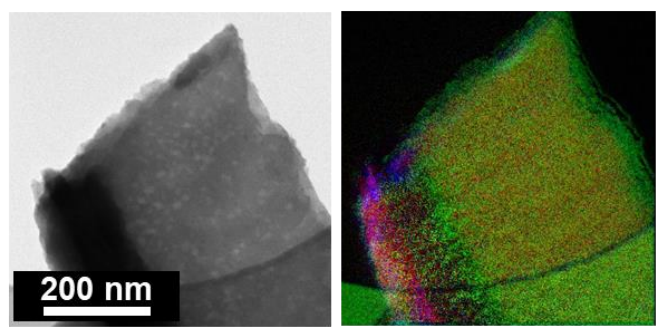
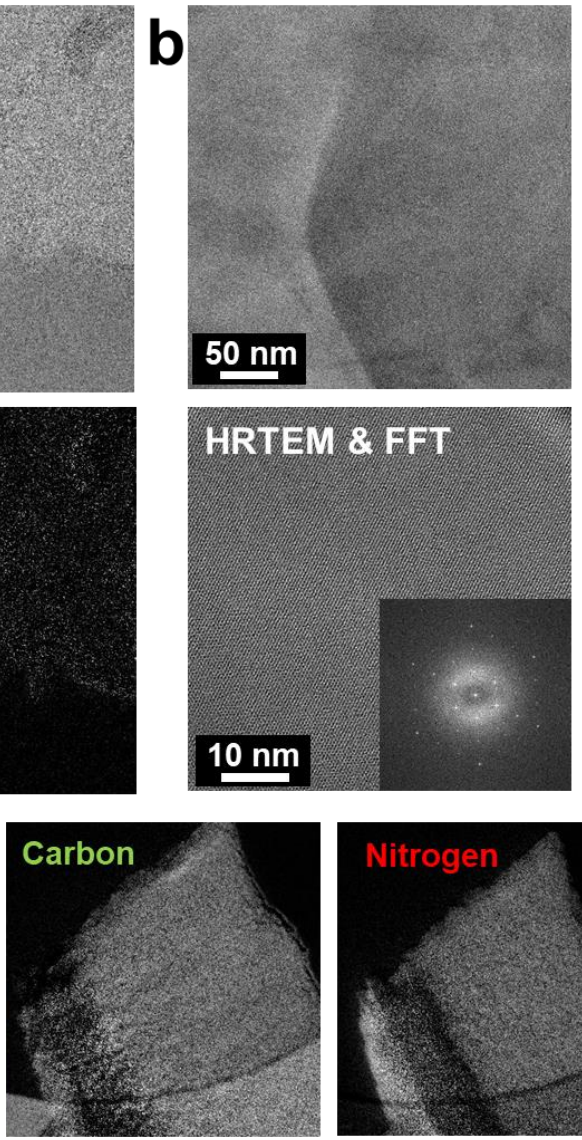
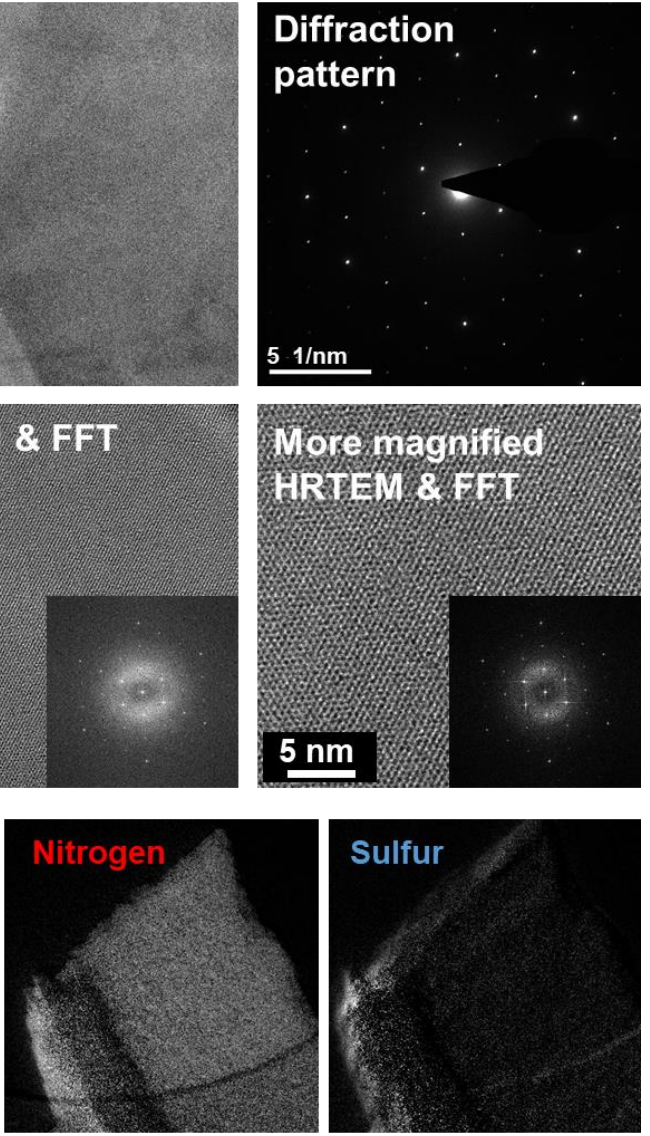

Figure 2. TEM analysis of the amorphous crystalline areas of the $\mathrm{CN}_{x}-\left\{\mathrm{Mo}_{3}\right\}$ (10 wt $\%$ loading) sample. (a): Bright-field image of the amorphous area and corresponding energy filtered images showing the distribution of carbon, nitrogen and sulfur. (b) Overview image, diffraction pattern and HRTEM images with corresponding local FFT patterns of a crystalline area of the sample. (c) Large overview image and corresponding elemental distributions of a crystalline flake of the sample.

Another indirect indication of the homogeneous distribution of the $\left\{\mathrm{Mo}_{3}\right\}$ clusters within $\mathrm{CN}_{\mathrm{x}}$ can be obtained from the TG data (Fig. 3a, ESI Fig. S3). The decomposition onset is shifted by ca. $100{ }^{\circ} \mathrm{C}$ 
towards the low-temperature region for the $\mathrm{CN}_{x^{-}}\left\{\mathrm{Mo}_{3}\right\}$ sample as compared to pristine $\mathrm{CN}_{\mathrm{x}}$ (Fig. 3a). This increase of the thermal decomposition rate of the hybrid is due to the solid acid-catalyzed effect of the highly dispersed $\left\{\mathrm{Mo}_{3}\right\}$ clusters or Mo oxides, which might be formed under thermal treatment in air. A similar effect was also reported for other metal oxide-doped polymeric carbon nitride systems. $^{34}$

The optical absorption edge of $\mathrm{CN}_{\mathrm{x}}$ remains the same after the incorporation of the $\left\{\mathrm{Mo}_{3}\right\}$ clusters (Fig. 3b); the only additional feature is a broad absorption tail in the visible region that can be attributed to electronic transitions within finely distributed $\left\{\mathrm{Mo}_{3}\right\}$ clusters.
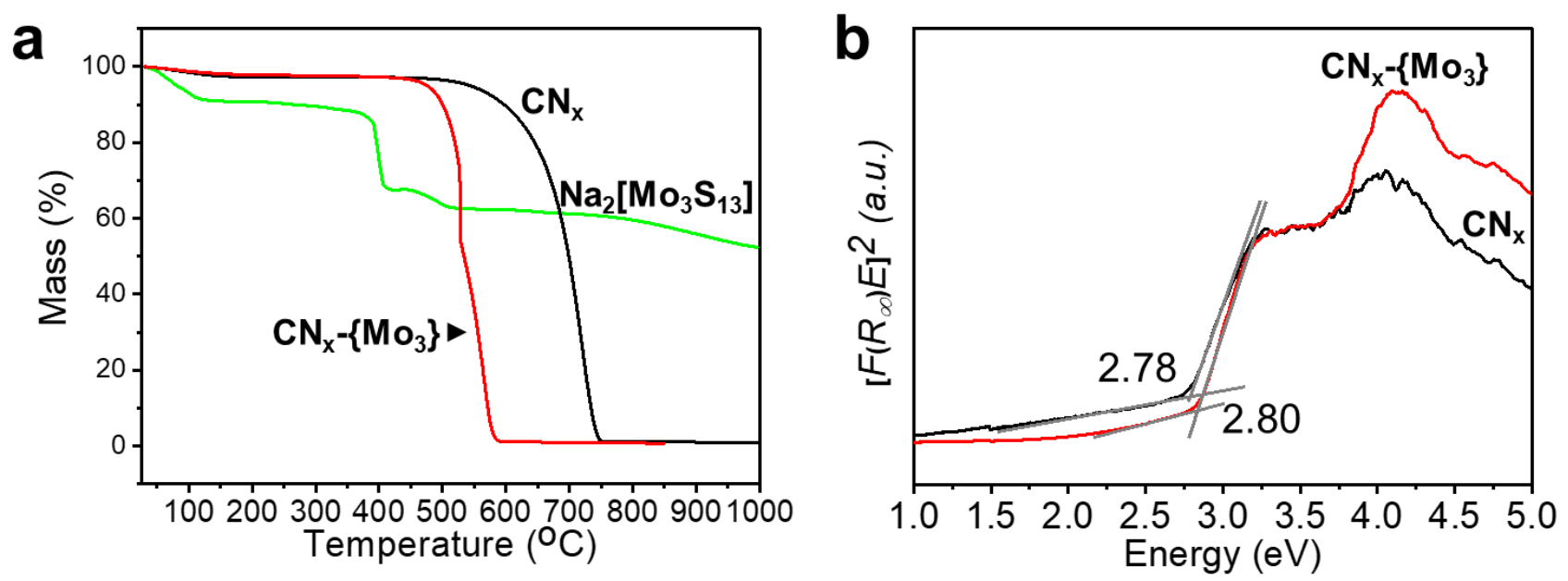

Figure 3. (a) Thermogravimetric analysis of the prepared materials in air and (b) Tauc-plots of the studied $\mathrm{CN}_{\mathrm{x}}$ photocatalysts with and without $\left\{\mathrm{Mo}_{3}\right\}$ clusters (10 wt \% loading).

\section{Light-driven hydrogen evolution}

The importance of ultrasonication during the depostition of co-catalyst is illustrated by the increased activity of the ultrasonicated materials in photocatalytic HER (ESI, Fig. S4). Henceforth, this procedure was applied to all photocatalysts discussed below. Preliminary experiments were performed to establish the optimal conditions for carrying out photocatalytic HER reactions in suspensions of the prepared materials. These initial investigations showed that optimum $\left\{\mathrm{Mo}_{3}\right\}$ cluster loading onto $\mathrm{CN}_{\mathrm{x}}$ was $10 \mathrm{wt} \%$ (ESI, Fig. S1), and subsequently other conditions were optimized for the $\mathrm{CN}_{\mathrm{x}^{-}}\left\{\mathrm{Mo}_{3}\right\}$ sample permitting it to attain its highest activity using $10 \mathrm{mg}$ of the photocatalyst in $10 \mathrm{ml}$ of a $\mathrm{H}_{2} \mathrm{O}: \mathrm{MeOH}(9: 1, \mathrm{v}: \mathrm{v})$ solution with near neutral $\mathrm{pH}$. The presence of $10 \%$ 
$\mathrm{MeOH}$ in the reaction medium, apart from playing a role of sacrificial reducing agent, also inhibits ligand-exchange reaction of the $\left\{\mathrm{Mo}_{3}\right\}$ cluster, where surface $\mathrm{S}_{2}{ }^{2-}$ might be gradually exchanged with hydroxide or water ligands. ${ }^{27}$ The pristine carbon nitride sample $\left(\mathrm{CN}_{\mathrm{x}}\right)$ does not show any significant $\mathrm{H}_{2}$ evolution activity under given conditions (Fig. 4a), while the $\mathrm{CN}_{\mathrm{x}}-\left\{\mathrm{Mo}_{3}\right\}$ is clearly active in this reaction. Few points are noteworthy in this context. Firstly, $\left\{\mathrm{Mo}_{3}\right\}$ clusters trigger the photocatalytic $\mathrm{H}_{2}$ evolution even in the presence of methanol, a much weaker reducing agent than lactic acid used by Wang et al. ${ }^{25}$ Not surprisingly, the activity towards $\mathrm{H}_{2}$ evolution can be enhanced by the application of additional electron donor such as ascorbic acid (ESI, Fig. S5, Fig. 4b). Furthermore, though the activity of $\mathrm{CN}_{\mathrm{x}}-\left\{\mathrm{Mo}_{3}\right\}$ is well below that of the benchmark Pt- $\mathrm{CN}_{\mathrm{x}}$ (Fig. 4a), we note that platinum is more expensive than molybdenum by the factor of $\sim 1000$, which eventually might become a determinative factor for the development of such systems. Interestingly, addition of an alternative widely used sacrificial reducing agent, triethanolamine (TEOA), lowered the yield of $\mathrm{H}_{2}$ (Fig. 4b), which can be explained by the decomposition of $\left\{\mathrm{Mo}_{3}\right\}$ clusters in the highly basic solution of TEOA.
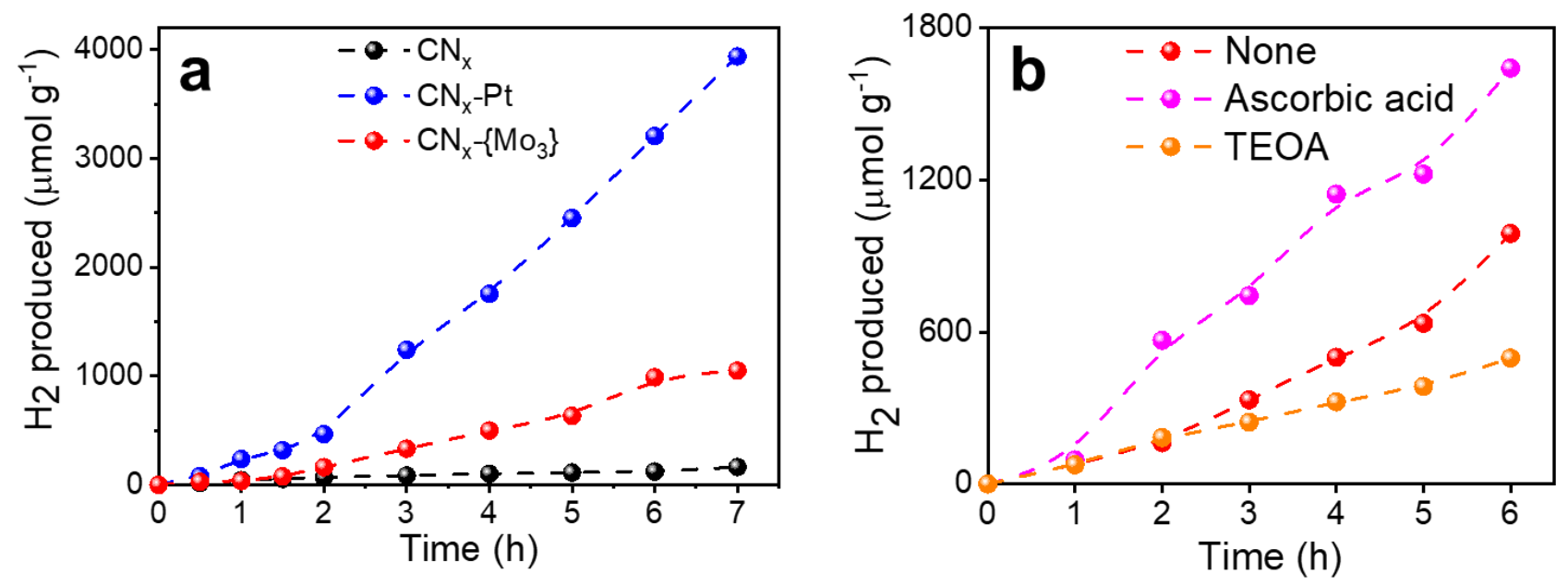

Figure 4: Photocatalytic HER performed using $\mathrm{CN}_{\mathrm{x}}$ based materials under $420 \mathrm{~nm}$ irradiation. Conditions: [catalyst] : 10mg, Solvent: $10 \mathrm{ml} \mathrm{H}_{2} \mathrm{O}: \mathrm{MeOH}(9: 1, \mathrm{v}: \mathrm{v})$, (a) in absence and (b) presence of additional electron donors [Triethanolamine] : $10 \%$ or [Ascorbic Acid] : $0.1 \mathrm{M}$.

\section{Optical spectroscopy of $\mathrm{CN}_{\mathrm{x}}-\{\mathrm{Moz}\}$}

To investigate the excitonic processes involved in the system, we performed steady-state photoluminescence (PL), time-resolved PL and fs-transient absorption (fs-TA) measurements. 
Figures 5a,b depict the photoluminescence properties of pristine $\mathrm{CN}_{\mathrm{x}}$ and $\mathrm{CN}_{\mathrm{x}}-\left\{\mathrm{Mo}_{3}\right\}$ upon $380 \mathrm{~nm}$ excitation. All samples show identical photoluminescence spectra peaking at $440 \mathrm{~nm}$ corresponding to optical bandgap emission. Compared to pristine $\mathrm{CN}_{\mathrm{x}}$, addition of $\left\{\mathrm{Mo}_{3}\right\}$ at the loading of $10 \mathrm{wt} \%$ and $20 \mathrm{wt} \%$ quenches the emission, which indicates an enhanced separation efficiency of the photoinduced charge carriers at the interface of higher loading samples. However, at a very low loading ( $2 \mathrm{wt} \%)$, we observed an increase of the emission intensity. In order to explain this finding, we propose that the addition of few $\left\{\mathrm{Mo}_{3}\right\}$ clusters leads to a situation in which the negatively charged clusters preferentially interact with the amine groups thereby breaking the amine hydrogen bonds with water or/and heptazine nitrogen atoms. The amine groups are apparently associated with shallow trapping states, ${ }^{35,36}$ which upon addition of only $2 \mathrm{wt} \%\left\{\mathrm{Mo}_{3}\right\}$ shift in energy and can thermally repopulate emissive excitonic states. This is in line with the increase of the photoluminescence lifetime from 3.02 (pristine $\mathrm{CN}_{\mathrm{x}}$ ) to $5.49 \mathrm{~ns}$ (upon addition of $2 \mathrm{wt} \%\left\{\mathrm{Mo}_{3}\right\}$ ). The dropping photoluminescence intensity in $10 \mathrm{wt} \% \mathrm{CN}_{\mathrm{x}}-\left\{\mathrm{Mo}_{3}\right\}$ correlates with the shortened emission lifetime, which drops back to $3.18 \mathrm{~ns}$. This indicates that, while the radiative rates of $2 \mathrm{wt} \%$ and $10 \mathrm{wt} \% \mathrm{CN}_{\mathrm{x}}$ $\left\{\mathrm{Mo}_{3}\right\}$ remain comparable, the addition of larger number of $\left\{\mathrm{Mo}_{3}\right\}$ clusters leads to an increased nonradiative decay of the bandgap emission. Such non-radiative decay channel is likely associated with the dissociation of band-edge or shallow trapped excitons into charge carriers at the $\mathrm{CN}_{\mathrm{x}}-\left\{\mathrm{Mo}_{3}\right\}$ interfaces. Considering the non-radiative decay in $10 \mathrm{wt} \% \mathrm{CN}_{\mathrm{x}}-\left\{\mathrm{Mo}_{3}\right\}$ to consist of an intrinsic nonradiative decay channel, which is also present in $2 \mathrm{wt} \% \mathrm{CN}_{\mathrm{x}^{-}}-\left\{\mathrm{Mo}_{3}\right\}$ and an additional decay channel induced by the increased cluster concentration, one can consider $k_{n r}{ }^{10 w t \%}=k_{n r}{ }^{2 w t \%}+k_{n r}{ }^{\left\{M o_{3}\right\}}$. Based on the photoluminescence decay times and under the assumption that the radiative rates remain unchanged one yields $k_{n r}{ }^{\left\{\mathrm{Mo}_{3}\right\}}=13.2 \cdot 10^{7} / \mathrm{sec}$, which can be considered the rate of cluster induced charge carrier generation from shallow trapped excitons in $10 \mathrm{wt} \% \mathrm{CN}_{\mathrm{x}}-\left\{\mathrm{Mo}_{3}\right\}$. 

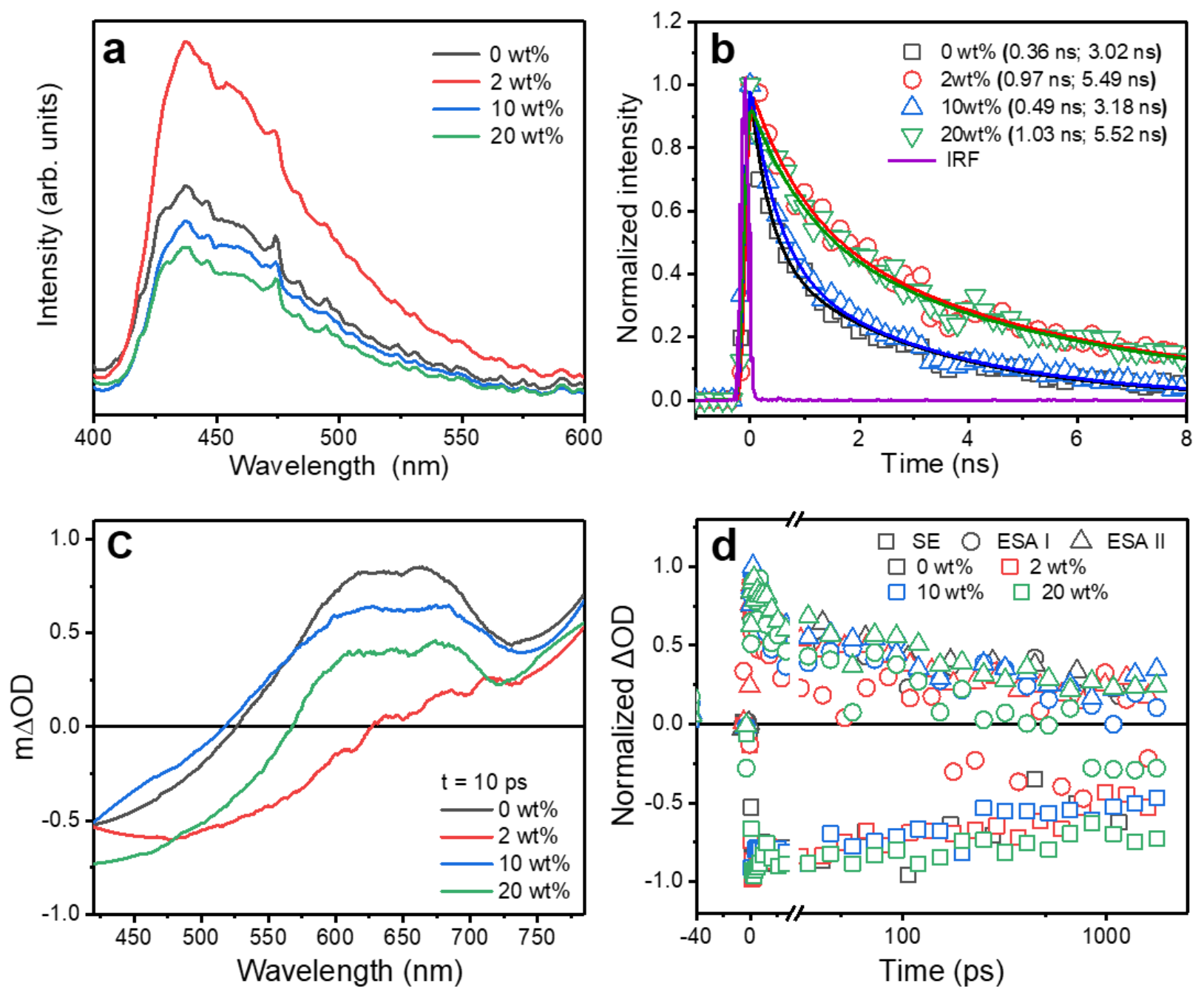

Figure 5: (a) Steady-state photoluminescence spectra of $\mathrm{CN}_{\mathrm{x}}$ suspensions at different loading ratios of $\left\{\mathrm{Mo}_{3}\right\}$. The spectra were recorded upon excitation at $380 \mathrm{~nm}$. (b) Time-resolved photoluminescence decay curves of $\left\{\mathrm{Mo}_{3}\right\}$ functionalized $\mathrm{CN}_{\mathrm{x}}$ suspensions $\left(2 \mathrm{mg} \mathrm{mL}^{-1}\right)$ after $385 \mathrm{~nm}$ photoexcitation. The photoluminescence decay curves were generated by spectrally integrating streak camera data between 410 and $550 \mathrm{~nm}$. (c) Transient absorption spectra taken upon excitation at $325 \mathrm{~nm}$ with a pump-probe delay of $10 \mathrm{ps}$. The spectra were smoothed by Savitzky-Golay method to reduce highfrequency noise from scattering; the original data are shown in the ESI (Figure S6). (d) fs-transient absorption decay kinetics of $\mathrm{CN}_{\mathrm{x}}$ materials dispersed in $\mathrm{H}_{2} \mathrm{O}$ upon $325 \mathrm{~nm}$ excitation. The pump pulses carried an energy of $0.3 \mu \mathrm{J}$ per pulse. The transient absorption kinetics depicted were generated by spectrally integrating the transient absorption data in the probe wavelength ranges indicated in panel $(\mathbf{c})$. GSB = ground state bleach; SE = stimulated emission; ESA = excitedstate absorption.

Upon increasing the loading to $20 \mathrm{wt} \%\left\{\mathrm{Mo}_{3}\right\}$, the lifetime of the emission increases again (to $5.52 \mathrm{~ns}$ ) while the emission yield, as indirectly reflected in the photoluminescence intensity remains constant at best. Assuming that the non-radiative rates associated with charge generation are at least as high as in $10 \mathrm{wt} \%\left\{\mathrm{Mo}_{3}\right\}$, we have to conclude that the radiative rate drops upon increasing the cluster loading. 
This illustrates that high catalyst loading impacts the electronic structure of the underlying $\mathrm{CN}_{\mathrm{x}}$ material causing the radiative rates to drop. It should be pointed out that the discussion laid out before is based on the two long lifetimes obtained from the bi-exponential fit of the photoluminescence decay. Figure S8 in ESI depicts the spectral components associated with the few-ns component and the sub-ns component. Considering the spectral characteristics of the components, we conclude that the blue-shifted short-lived photoluminescence stems from the band-edge emission, while the slower component reflects the decay of weakly trapped excitons. ${ }^{37}$ In addition to the discussion above, we observe that the overall weight of the short-lived component to the time-resolved photoluminescence data decreases upon addition of $\left\{\mathrm{Mo}_{3}\right\}$ clusters to the $\mathrm{CN}_{\mathrm{x}}$ material. We associate this trend with an increased probability of bandgap exciton quenching by $\left\{\mathrm{Mo}_{3}\right\}$ cluster-induced charge separation.

Next, we will consider fs transient absorption data recorded for the differently loaded $\mathrm{CN}_{\mathrm{x}}$ materials upon excitation at $325 \mathrm{~nm}$. Given the specific experimental setup, the data are recorded up to delay times of $1.8 \mathrm{~ns}$. The transient absorption spectra recorded at a pump-probe delay of $10 \mathrm{ps}$ (see Figure 5c) show a region of negative feature, which contains contributions from ground state bleach (GSB) and stimulated emission (SE) and two excited-state absorption (ESA) features, one at roughly 650 $\mathrm{nm}$ and one peaking towards the near-IR. The contribution from SE is apparent when comparing the shape of the negative transient absorption feature: for $2 \mathrm{wt} \%\left\{\mathrm{Mo}_{3}\right\}$, the sample with the highest emission intensity, the negative band extends furthest to the red and partially overlaps with the visible ESA band (which we refer to as ESA I).

To compare the photoinduced kinetics for the different materials, the characteristic transient absorption signals, i.e. GSB, the ESA in the visible and near-IR regions (Figure 5c), are spectrally integrated in the respective wavelength ranges. The resultant kinetics are normalized and depicted in Figure 5d. It is apparent that the addition of the $\left\{\mathrm{Mo}_{3}\right\}$ catalysts does not impact the ultrafast photoinduced kinetics in the $\mathrm{CN}_{\mathrm{x}}$ materials. Similar results are also observed for $\mathrm{CN}_{\mathrm{x}}$ samples loaded with Pt-nanoparticles as a catalyst (see Figure S7), where the time resolved PL and transient absorption data do not show any significant changes compared to experiments done with $\mathrm{CN}_{\mathrm{x}}$ alone. 
The data for the $\mathrm{CN}_{\mathrm{x}}$-Pt samples can also be understood in terms of an excited state decay following a power-law dependence and thus implying a trap-assisted recombination process. ${ }^{38-40}$ This is reminiscent of the results obtained for polymeric carbon nitride modified with $\mathrm{Pt}$ via photodeposition. ${ }^{40}$

\section{Photopotential transient measurements}

While the fs transient absorption data indicate ultrafast photoinduced kinetics (on ps timescale), which are not notably affected by the molecular $\left\{\mathrm{Mo}_{3}\right\}$ catalyst, our photoluminescence quenching experiments revealed that the addition of larger amounts of $\left\{\mathrm{Mo}_{3}\right\}$ catalyst is likely associated with the dissociation of the band-edge and/or shallow trapped excitons into charge carriers, i.e. to increased charge separation. Furthermore, we observed a significant effect of the catalyst on the photocatalytic turnover (Figure 4). As the catalysis typically occurs on a rather slow time scale, we envisaged that the catalyst effects could be possibly followed by open-circuit photopotential transient measurements. ${ }^{41-44}$ Indeed, this is the case as evidenced by the stark difference in photopotential transients recorded for $\mathrm{CN}_{\mathrm{x}}$ powders (with and without catalysts) after deposition onto FTO glass (Fig. 6a). In such a system, the sign of the photopotential is determined by the competitive kinetics of electron and hole transfers at the $\mathrm{FTO} / \mathrm{CN}_{\mathrm{x}}$ and $\mathrm{CN}_{\mathrm{x}} /($ catalyst $) /$ solution interfaces. The very small values of the photopotentials, as compared to conventional semiconductors, are related to the strongly insulating character of polymeric $\mathrm{CN}_{\mathrm{x}},{ }^{45}$ and to the rather low quality of electric contact between $\mathrm{CN}_{\mathrm{x}}$ and FTO. Notably, pristine $\mathrm{CN}_{\mathrm{x}}$ without any catalyst exhibits small negative photopotentials, meaning that the photogenerated electrons do not readily react with the electrolyte, but are instead accumulated in $\mathrm{CN}_{\mathrm{x}}$ and in the underlying FTO substrate. In contrast, after introducing the catalysts, either $\mathrm{Pt}$ or $\left\{\mathrm{Mo}_{3}\right\}$, the photopotential behaviour is completely reversed and the photopotentials are positive now. This shows that, in the presence of the catalyst, the photogenerated electrons are more effectively extracted by the catalyst - as already corroborated by the observed decrease of the photoluminescence intensity and increase of the non-radiative decay into the charge separated state - and channelled to protons in solution, while the oxidizing equivalents (holes) are accumulated in 
$\mathrm{CN}_{\mathrm{x}}$ and shift the Fermi level of the FTO to more positive potentials (Fig. 6b). This experiment clearly confirms, in analogy to conventional Pt hydrogen evolution catalyst, ${ }^{46}$ the strong effect of molecular $\left\{\mathrm{Mo}_{3}\right\}$ clusters on exciton dissociation and unidirectional transfer of trapped electrons from $\mathrm{CN}_{\mathrm{x}}$ to protons in the solution.

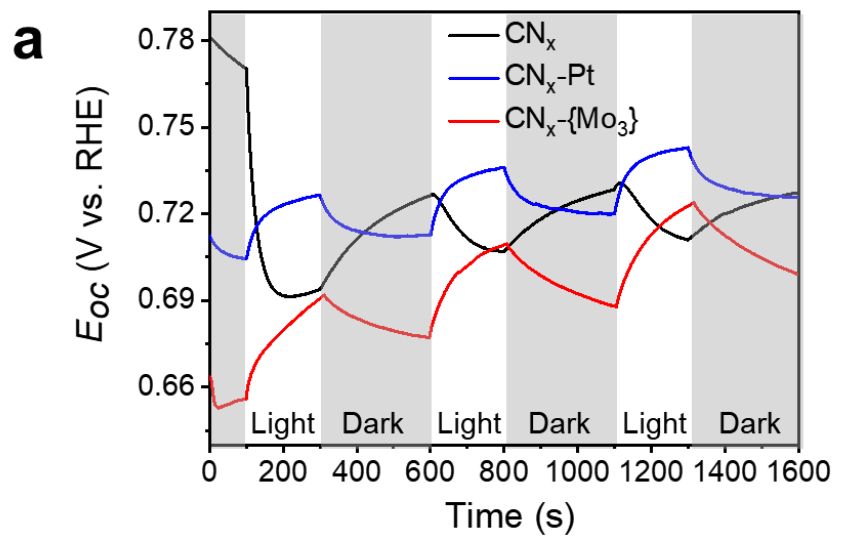

b

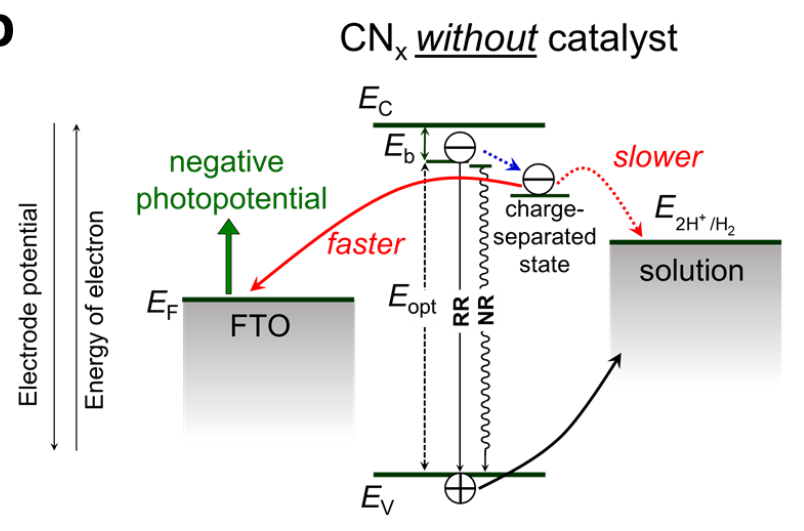

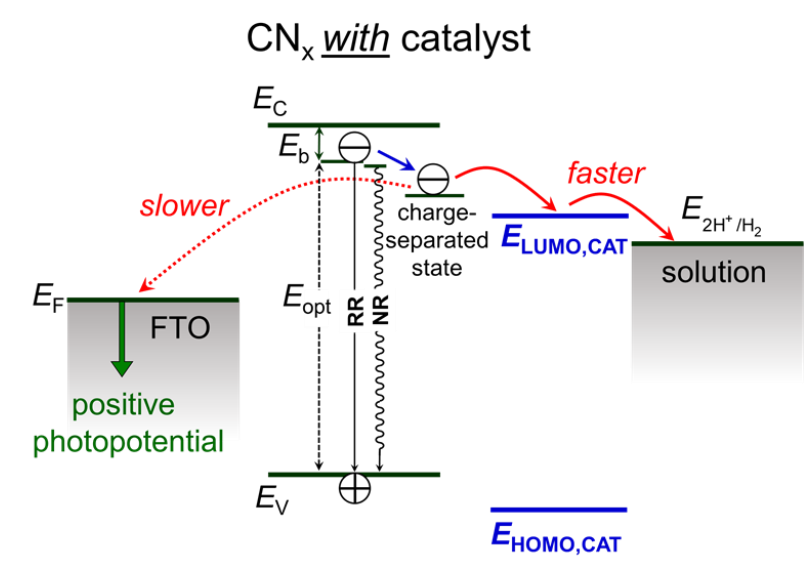

Figure 6. (a) Open-circuit photopotential measurements of the $\mathrm{CN}_{\mathrm{x}}, \mathrm{CN}_{\mathrm{x}}-\mathrm{Pt}$ and $\mathrm{CN}_{\mathrm{x}}-\left\{\mathrm{Mo}_{3}\right\}$ samples recorded in an aqueous $\mathrm{LiClO}_{4}(0.1 \mathrm{M} ; \mathrm{pH}$ 7) electrolyte (the solution was purged with argon prior to experiments); the materials were deposited on FTO and irradiated from the backside with monochromatic light $(\lambda=380 \mathrm{~nm}$ ); (b) A simplified scheme showing the generation of photopotential at $\mathrm{FTO} / \mathrm{CN}_{\mathrm{x}}$ photoelectrodes without and with the $\left\{\mathrm{Mo}_{3}\right\}$ catalyst: $E_{\mathrm{c}}$ and $E_{\mathrm{v}}$ stand for the conduction and valence band edge of $\mathrm{CN}_{\mathrm{x}} ; \mathbf{R R}$ and $\mathbf{N R}$ stand for radiative and non-radiative recombination from emissive (band-edge) and non-emissive (shallow-trap) excitonic states, respectively; other recombination pathways are omitted for the sake of clarity; $E_{\mathrm{opt}}$ designates the optical bandgap of $\mathrm{CN}_{\mathrm{x}}, E_{\mathrm{b}}$ stands for the exciton binding energy and was estimated as $\sim 0.3 \mathrm{eV}$ according to Ref. ${ }^{46}$, the HOMO-LUMO gap of the catalyst has been estimated as $2.5 \mathrm{eV}$ by DFT calculations (see the ESI for details).

\section{Conclusions}

The electron accumulation in polymeric carbon nitride photocatalysts is known to be one of the major bottlenecks in light-driven hydrogen evolution, ${ }^{47,48}$ and has been typically addressed by deposition of 
$\mathrm{Pt},{ }^{48-50} \mathrm{Ni}$-based molecular catalysts, ${ }^{51-53}$ or enzymes. ${ }^{11,54} \mathrm{We}$ investigated polymeric carbon nitride coupled with thiomolybdate $\left\{\mathrm{Mo}_{3}\right\}$ clusters as an inexpensive alternative to widespread Pt-containing systems. The $\left\{\mathrm{Mo}_{3}\right\}$ clusters do promote the hydrogen evolution reaction under visible light irradiation in the presence of methanol or other (stronger) reducing agents, yet the activity of $\mathrm{CN}_{\mathrm{x}^{-}}$ $\left\{\mathrm{Mo}_{3}\right\}$ composites was found to be significantly lower than that of $\mathrm{CN}_{\mathrm{x}}-\mathrm{Pt}$ benchmark photocatalysts. While the deposition of the $\left\{\mathrm{Mo}_{3}\right\}$ clusters does not induce any significant structural alteration of the polymeric carbon nitride absorber, the loading of the $\left\{\mathrm{Mo}_{3}\right\}$ catalyst exerts an influence on exciton and charge transfer dynamics. At sub-optimal (low) $\left\{\mathrm{Mo}_{3}\right\}$ cluster loadings the excitons are trapped in shallow states within a few ns. These non-emissive excitonic states (shallow traps) are apparently in a thermal equilibrium with band-edge emissive states leading to enhanced photoluminescence. At higher $\left\{\mathrm{Mo}_{3}\right\}$ catalyst loading, the transient PL measurements show that the excitons dissociate more effectively, forming thus more populated charge-separated (deep trap) states. This is followed by more efficient electron transfer to the catalyst and protons in the solution, as indicated by the change of the sign of the open-circuit photopotential to positive (Fig. 6b). Finally, three points are noteworthy. First, the charge transfer to the catalyst, both molecular $\left\{\mathrm{Mo}_{3}\right\}$ clusters and $\mathrm{Pt}$ nanoparticles, definitely occurs on a relatively longer (ns-s) time scale, as neither $\left\{\mathrm{Mo}_{3}\right\}$ nor $\mathrm{Pt}$ catalysts had impact on the ultrafast (sub-ns) photoinduced kinetics in the $\mathrm{CN}_{\mathrm{x}}$ materials. These results are consistent with recent reports by Durrant et al, ${ }^{47}$ suggesting that generation of "long-lived" (> ns time scale) electrons is beneficial for enhancing the photoactivity in hydrogen evolution. Second, while the charge-separated deep trap states play an important role in the $\mathrm{CN}_{\mathrm{x}}-\left\{\mathrm{Mo}_{3}\right\}$ system by facilitating the exciton dissociation, it cannot be ruled out that they also act as recombination centers, which - in view of further improvements on photocatalytic activity of carbon nitrides - makes an elaborated engineering of their electronic and interfacial properties mandatory. Third, as the emissive decay kinetics shows an obvious deviation from pristine $\mathrm{CN}_{\mathrm{x}}$ at non-optimal catalyst loadings ( 2 and $20 \mathrm{wt} \%$ ) but not in case of the optimal loading (10 wt $\%$ ), the design and development 
of appropriate synthetic strategies for optimizing the catalyst loading without affecting negatively the electronic structure of the $\mathrm{CN}_{\mathrm{x}}$ materials is essential for enhancing the photoconversion efficiencies.

\section{Author contributions}

T.J., C.S., B.D., D.M. and R.B. conceived the research and lead the project. A.R., E.A., D.M., C.A. and I.K. performed the synthesis and characterization of materials, interpreted all data, and wrote the manuscript. J.B. and U.K. performed the TEM measurements and analysis. T.D. performed the XPS analysis. C.L. and B.D. performed the spectroscopy studies. J.B. and U.K. performed TEM characterization. C.I. and T.J. performed theoretical calculations. All authors wrote and commented on the manuscript.

\section{Conflict of interests}

The authors declare no competing interests.

\section{Acknowledgements}

This work was funded by the Deutsche Forschungsgemeinschaft (DFG, German Research Foundation) - Projektnummer 364549901 - TRR 234 CataLight [Projects A5, B6, and C4]. Computational resources were provided by the state of Baden-Württemberg through bwHPC and the DFG (INST 40/467-1 FUGG). I.K. acknowledges the support of the Alexander von Humboldt Foundation through the Humboldt Research Fellowship. 


\section{References}

1. J. Barber, Sustainable Energy Fuels., 2018, 2, 927-935.

2. A. Kudo and Y. Miseki, Chem. Soc. Rev., 2009, 38, 253-278.

3. X. Chen, S. Shen, L. Guo and S. S. Mao, Chem. Rev., 2010, 110, 6503-6570.

4. G. Zhang, Z.-A. Lan and X. Wang, Angew. Chem., Int. Ed., 2016, 55, 15712-15727.

5. M. F. Kuehnel and E. Reisner, Angew. Chem., Int. Ed., 2018, 57, 3290-3296.

6. X. Zou and Y. Zhang, Chem. Soc. Rev., 2015, 44, 5148-5180.

7. X. Wang, K. Maeda, A. Thomas, K. Takanabe, G. Xin, J. M. Carlsson, K. Domen and M. Antonietti, Nat. Mater., 2009, 8, 76-80.

8. X. Wang, K. Maeda, X. Chen, K. Takanabe, K. Domen, Y. Hou, X. Fu and M. Antonietti, J. Am. Chem. Soc., 2009, 131, 1680-1681.

9. $\quad$ N. Wang, J. Wang, J. Hu, X. Lu, J. Sun, F. Shi, Z.-H. Liu, Z. Lei and R. Jiang, ACS Appl. Energy Mater., 2018, 1, 2866-2873.

10. K. Maeda, X. Wang, Y. Nishihara, D. Lu, M. Antonietti and K. Domen, J. Phys. Chem. C, 2009, 113, 4940-4947.

11. C. A. Caputo, M. A. Gross, V. W. Lau, C. Cavazza, B. V. Lotsch and E. Reisner, Angew. Chem., Int. Ed., 2014, 53, 11538-11542.

12. J. Wang, J. Chen, P. Wang, J. Hou, C. Wang and Y. Ao, Appl. Catal. B: Environ., 2018, 239, 578-585.

13. Y. Wu, H. Wang, W. Tu, S. Wu, Y. Liu, Y. Z. Tan, H. Luo, X. Yuan and J. W. Chew, Appl. Catal. B: Environ., 2018, 229, 181-191.

14. Y. Hou, Y. Zhu, Y. Xu and X. Wang, Appl. Catal. B: Environ., 2014, 156-157, 122-127.

15. L. Ge, C. Han, X. Xiao and L. Guo, Int. J. Hydrogen Energy, 2013, 38, 6960-6969.

16. J. Kibsgaard, T. F. Jaramillo and F. Besenbacher, Nat. Chem., 2014, 6, 248-253.

17. H. I. Karunadasa, E. Montalvo, Y. Sun, M. Majda, J. R. Long and C. J. Chang, Science, 2012, 335, 698-702.

18. T. F. Jaramillo, K. P. Jørgensen, J. Bonde, J. H. Nielsen, S. Horch and I. Chorkendorff, Science, 2007, 317, 100-102.

19. K. Du, L. Zheng, T. Wang, J. Zhuo, Z. Zhu, Y. Shao and M. Li, ACS Appl. Mater. Interfaces, 2017, 9, 18675-18681.

20. Y. Shang, X. Xu, B. Gao and Z. Ren, ACS Sustainable Chem. Eng., 2017, 5, 8908-8917.

21. Y. Shang, X. Xu, Z. Wang, B. Jin, R. Wang, Z. Ren, B. Gao and Q. Yue, ACS Sustainable Chem. Eng., 2018, 6, 6920-6931.

22. M.-L. Grutza, A. Rajagopal, C. Streb and P. Kurz, Sustainable Energy Fuels., 2018, 2, 1893-1904.

23. D. Recatalá, R. Llusar, A. L. Gushchin, E. A. Kozlova, Y. A. Laricheva, P. A. Abramov, M. N. Sokolov, R. Gómez and T. Lana-Villarreal, ChemSusChem, 2015, 8, 1299-1299.

24. I. Romanenko, A. Rajagopal, C. Neumann, A. Turchanin, C. Streb and F. H. Schacher, J. Mater. Chem. A, 2020, 8, 6238-6244.

25. F. Guo, Y. Hou, A. M. Asiri and X. Wang, Chem. Commun., 2017, 53, 13221-13224. 
26. A. Rajagopal, F. Venter, T. Jacob, L. Petermann, S. Rau, S. Tschierlei and C. Streb, Sustainable Energy Fuels., 2019, 3, 92-95.

27. M. Dave, A. Rajagopal, M. Damm-Ruttensperger, B. Schwarz, F. Nägele, L. Daccache, D. Fantauzzi, T. Jacob and C. Streb, Sustainable Energy Fuels., 2018, 2, 1020-1026.

28. Y. Han, D. Yue, M. Kan, Y. Wu, J. Zeng, Z. Bian, Y. Zhao and X. Qian, Appl. Catal. B: Environ., 2019, 245, 190-196.

29. A. Müller, V. Wittneben, E. Krickemeyer, H. Bögge and M. Lemke, Z. Anorg. Allg. Chem., 1991, 605, 175-188.

30. R. Siebert, D. Akimov, M. Schmitt, A. Winter, U. S. Schubert, B. Dietzek and J. Popp, ChemPhysChem, 2009, 10, 910-919.

31. M. Ilkaeva, I. Krivtsov, E. Bartashevich, S. Khainakov, J. Garcia, E. Diaz and S. Ordonez, Green Chem., 2017, 19, 4299-4304.

32. I. Krivtsov, D. Mitoraj, C. Adler, M. Ilkaeva, M. Sardo, L. Mafra, C. Neumann, A. Turchanin, C. Li, B. Dietzek, R. Leiter, J. Biskupek, U. Kaiser, C. Im, B. Kirchhoff, T. Jacob and R. Beranek, Angew. Chem., Int. Ed., 2020, 59, 487-495.

33. C.-H. Lee, S. Lee, Y.-K. Lee, Y. C. Jung, Y.-I. Ko, D. C. Lee and H.-I. Joh, ACS Catal., $2018,8,5221-5227$.

34. Y. He, J. Cai, T. Li, Y. Wu, Y. Yi, M. Luo and L. Zhao, Ind. Eng. Chem. Res., 2012, 51, 14729-14737.

35. Y. Kang, Y. Yang, L.-C. Yin, X. Kang, L. Wang, G. Liu and H.-M. Cheng, Adv. Mater., 2016, 28, 6471-6477.

36. X. Li, I. V. Sergeyev, F. Aussenac, A. F. Masters, T. Maschmeyer and J. M. Hook, Angew. Chem., Int. Ed., 2018, 57, 6848-6852.

37. C. Merschjann, S. Tschierlei, T. Tyborski, K. Kailasam, S. Orthmann, D. Hollmann, T. Schedel-Niedrig, A. Thomas and S. Lochbrunner, Adv. Mater., 2015, 27, 7993-7999.

38. J. Nelson, Phys. Rev. B: Condens. Matter Mater. Phys., 1999, 59, 15374-15380.

39. J. J. Walsh, C. Jiang, J. Tang and A. J. Cowan, Phys. Chem. Chem. Phys., 2016, 18, 2482524829.

40. R. Godin, Y. Wang, M. A. Zwijnenburg, J. Tang and J. R. Durrant, J. Am. Chem. Soc., 2017, 139, 5216-5224.

41. D. Monllor-Satoca and R. Gomez, J. Phys. Chem. C, 2008, 112, 139-147.

42. S. Neubert, D. Mitoraj, S. A. Shevlin, P. Pulisova, M. Heimann, Y. Du, G. K. L. Goh, M. Pacia, K. Kruczala, S. Turner, W. Macyk, Z. X. Guo, R. K. Hocking and R. Beranek, J. Mater. Chem. A, 2016, 4, 3127-3138.

43. S. Neubert, P. Pulisova, C. Wiktor, P. Weide, B. Mei, D. A. Guschin, R. A. Fischer, M. Muhler and R. Beranek, Catal. Today, 2014, 230, 97-103.

44. C. Adler, D. Mitoraj, I. Krivtsov and R. Beranek, J. Chem. Phys., 2020, 152, 244702.

45. M. Bledowski, L. Wang, A. Ramakrishnan, O. V. Khavryuchenko, V. D. Khavryuchenko, P. C. Ricci, J. Strunk, T. Cremer, C. Kolbeck and R. Beranek, Phys. Chem. Chem. Phys., 2011, 13, 21511-21519.

46. S. Melissen, T. Le Bahers, S. N. Steinmann and P. Sautet, J. Phys. Chem. C, 2015, 119, 25188-25196. 
47. W. Yang, R. Godin, H. Kasap, B. Moss, Y. Dong, S. A. J. Hillman, L. Steier, E. Reisner and J. R. Durrant, J. Am. Chem. Soc., 2019, 141, 11219-11229.

48. V. W.-h. Lau, D. Klose, H. Kasap, F. Podjaski, M.-C. Pignié, E. Reisner, G. Jeschke and B. V. Lotsch, Angew. Chem., Int. Ed., 2017, 56, 510-514.

49. D. J. Martin, K. Qiu, S. A. Shevlin, A. D. Handoko, X. Chen, Z. Guo and J. Tang, Angew. Chem., Int. Ed., 2014, 53, 9240-9245.

50. D. J. Martin, P. J. T. Reardon, S. J. A. Moniz and J. Tang, J. Am. Chem. Soc., 2014, 136, 12568-12571.

51. T. Uekert, H. Kasap and E. Reisner, J. Am. Chem. Soc., 2019, 141, 15201-15210.

52. H. Kasap, R. Godin, C. Jeay-Bizot, D. S. Achilleos, X. Fang, J. R. Durrant and E. Reisner, ACS Catal., 2018, 8, 6914-6926.

53. H. Kasap, C. A. Caputo, B. C. M. Martindale, R. Godin, V. W.-h. Lau, B. V. Lotsch, J. R. Durrant and E. Reisner, J. Am. Chem. Soc., 2016, 138, 9183-9192.

54. C. A. Caputo, L. Wang, R. Beranek and E. Reisner, Chem. Sci., 2015, 6, 5690-5694. 
TOC graphic

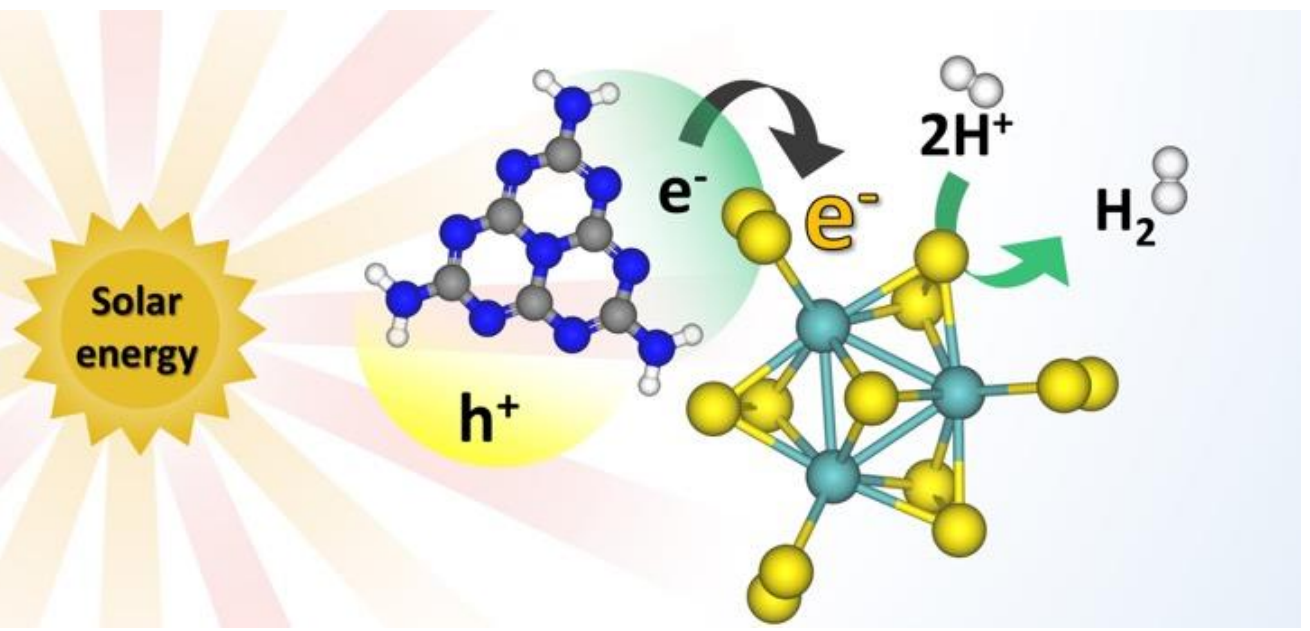




\section{SUPPLEMENTARY INFORMATION}

\section{Polymeric carbon nitride coupled with a molecular thiomolybdate catalyst: exciton and charge dynamics in light-driven hydrogen evolution}

Ashwene Rajagopal, ${ }^{a}$ Elham Akbarzadeh, ${ }^{a}$ Chunyu Li, ${ }^{b, c}$ Dariusz Mitoraj, ${ }^{d}$ Igor Krivtsov, ${ }^{d, *}$

Christiane Adler, ${ }^{d}$ Thomas Diemant, ${ }^{e}$ Johannes Biskupek, ${ }^{f}$ Ute Kaiser, ${ }^{f}$ Changbin Im, ${ }^{d}$ Magdalena Heiland, ${ }^{a}$ Timo Jacob,${ }^{d, g, h}$ Carsten Streb,${ }^{a, g, h} *$ Benjamin Dietzek, ${ }^{b, c, i} *$ Radim Beranek $^{d, *}$

a Institute of Inorganic Chemistry I, Ulm University, Albert-Einstein-Allee 11, 89081 Ulm, Germany

$b \quad$ Institute of Physical Chemistry and Abbe Center of Photonics, Friedrich Schiller University Jena, Lessingstr. 10, 07743 Jena, Germany

c Department Functional Interfaces, Leibniz Institute of Photonic Technology (IPHT), Albert-Einstein-Str. 9, 07745 Jena, Germany

d Institute of Electrochemistry, Ulm University, Albert-Einstein-Allee 47, 89081 Ulm, Germany

e Institute of Surface Chemistry and Catalysis, Ulm University, Albert-Einstein-Allee 47, 89081 Ulm, Germany

f Electron Microscopy of Materials Science, Central Facility for Electron Microscopy, Ulm University, AlbertEinstein-Allee 11, 89081, Ulm, Germany

g Helmholtz-Institute-Ulm (HIU), Helmholtzstr. 11, 89081, Ulm, Germany

h Karlsruhe Institute of Technology (KIT), P.O. Box 3640, 76021, Karlsruhe, German

${ }^{i} \quad$ Center for Energy and Environmental Chemistry Jena (CEEC Jena), Philosophenweg 7a, 07743 Jena, Germany

*Corresponding authors: igor.krivtsov@uni-ulm.de, carsten.streb@uni-ulm.de, benjamin.dietzek@uni-jena.de, radim.beranek@uni-ulm.de 


\section{Preliminary photocatalytic study:}

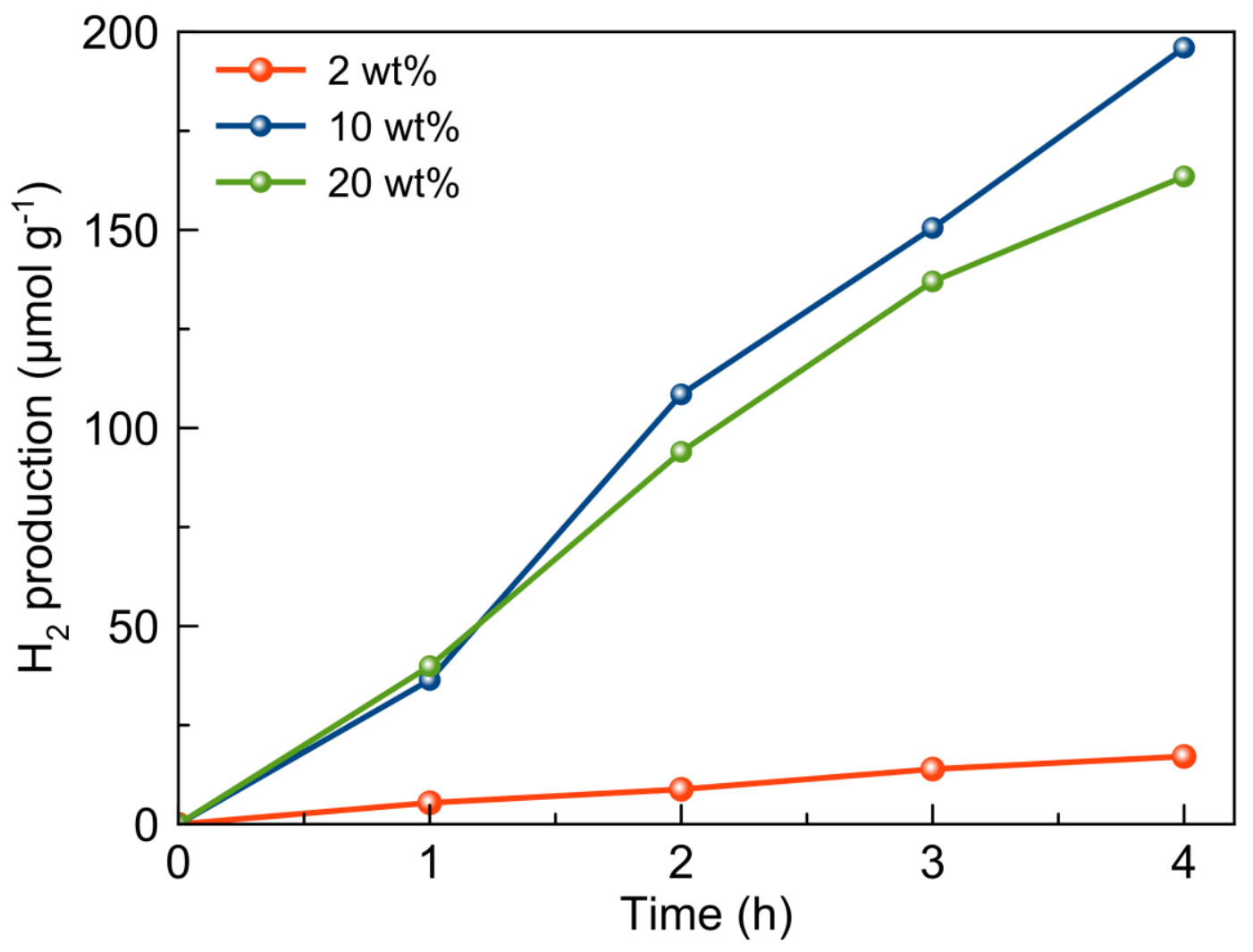

Figure S1. Photocatalytic HER performed using $\mathrm{CN}_{\mathrm{x}}$ based materials with varied loading of $\left\{\mathrm{Mo}_{3}\right\}$ clusters under $420 \mathrm{~nm}$ irradiation. Conditions: [catalyst]: $10 \mathrm{mg}$, Solvent: $10 \mathrm{ml} \mathrm{H} \mathrm{H}_{2} \mathrm{O}: \mathrm{MeOH}$ (9:1, $\mathrm{v}: \mathrm{v})$. Note that the hydrogen production rates in these preliminary measurements were lower than in the rest of the study due to a difference in geometry of the reaction cell which resulted in different absorbed photon flux.

\section{FTIR analysis:}

FT-IR spectra of $\mathrm{CN}_{\mathrm{x}}, \mathrm{Na}_{2}\left[\mathrm{Mo}_{3} \mathrm{~S}_{13}\right]$ and $\left\{\mathrm{Mo}_{3}\right\} @ \mathrm{CN}_{\mathrm{x}}$ nanocomposite are displayed in Figure $1 \mathrm{~b}$. In the FT-IR spectrum of $\mathrm{CN}_{\mathrm{x}}$ and $\left\{\mathrm{Mo}_{3}\right\} @ \mathrm{CN}_{\mathrm{x}}$ hybrid the peaks at around $1639 \mathrm{~cm}^{1-}$ can be ascribed to $\mathrm{C}-\mathrm{N}$ stretching vibration modes and the peaks at 1245,1329 and $1416 \mathrm{~cm}^{1-}$ are attributed to the aromatic $\mathrm{C}-\mathrm{N}$ stretching. The sharp peak at $806 \mathrm{~cm}^{1-}$ is related to the out-of-plane bending vibration of heterocyclic C-N. The broad peak at around $2900-3400 \mathrm{~cm}^{1-}$ can be related to the stretching modes of the $\mathrm{N}-\mathrm{H}$ bond and the hydroxyl group of the adsorbed water. For the pure $\mathrm{Na}_{2}\left[\mathrm{Mo}_{3} \mathrm{~S}_{13}\right]$, the spectrum displays a sharp peak at $1138 \mathrm{~cm}^{1-}$ which can be assigned to the $\mathrm{SO}_{4}{ }^{2-}$ group in the compound which probably is produced during the cation exchange process. However, no distinct sign of $\left[\mathrm{Mo}_{3} \mathrm{~S}_{13}\right]^{2-}$ cluster is obvious in the FT-IR spectrum of $\left\{\mathrm{Mo}_{3}\right\} @ \mathrm{CN}_{\mathrm{x}}$ composite, which can be because of the little amount of $\left\{\mathrm{Mo}_{3}\right\}$ in the hybrid and also existence of $\mathrm{CN}_{\mathrm{x}}$. 

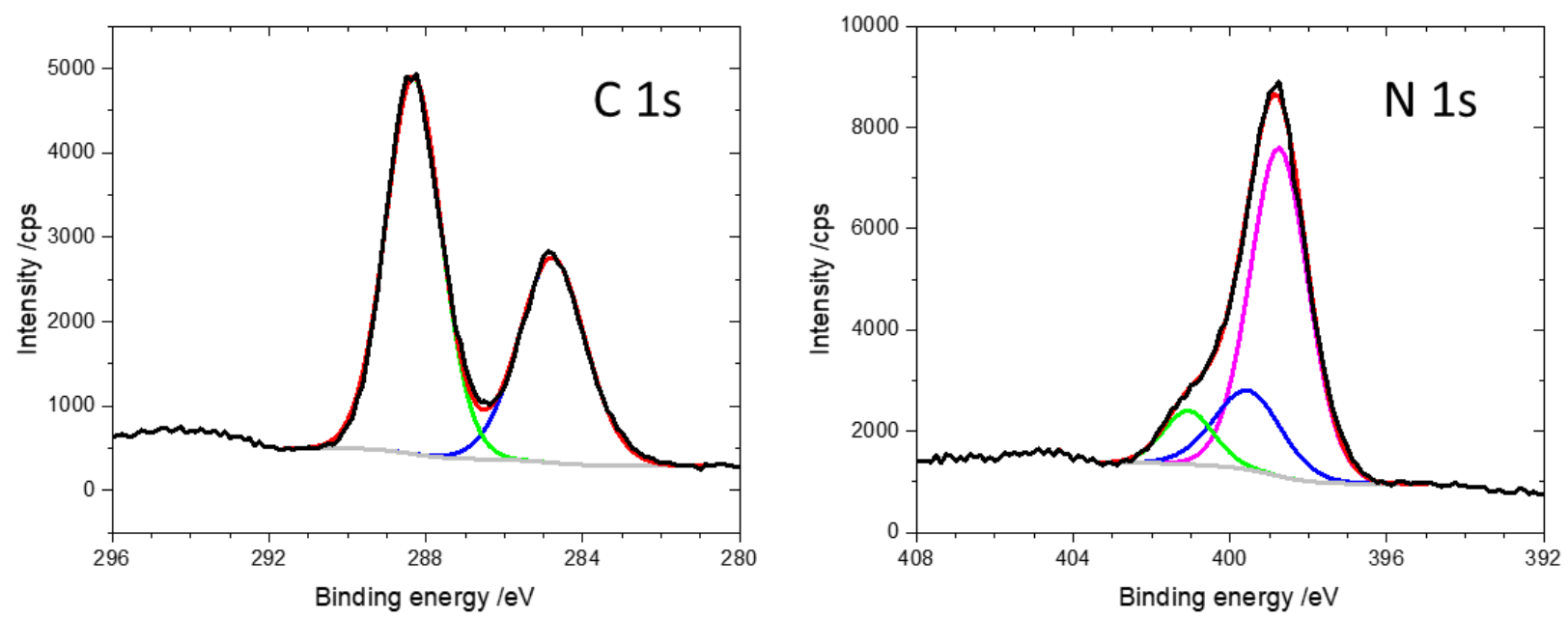

Figure S2. XPS C 1s and N 1s spectra of $\mathrm{CN}_{\mathrm{x}}-\left\{\mathrm{Mo}_{3}\right\}$

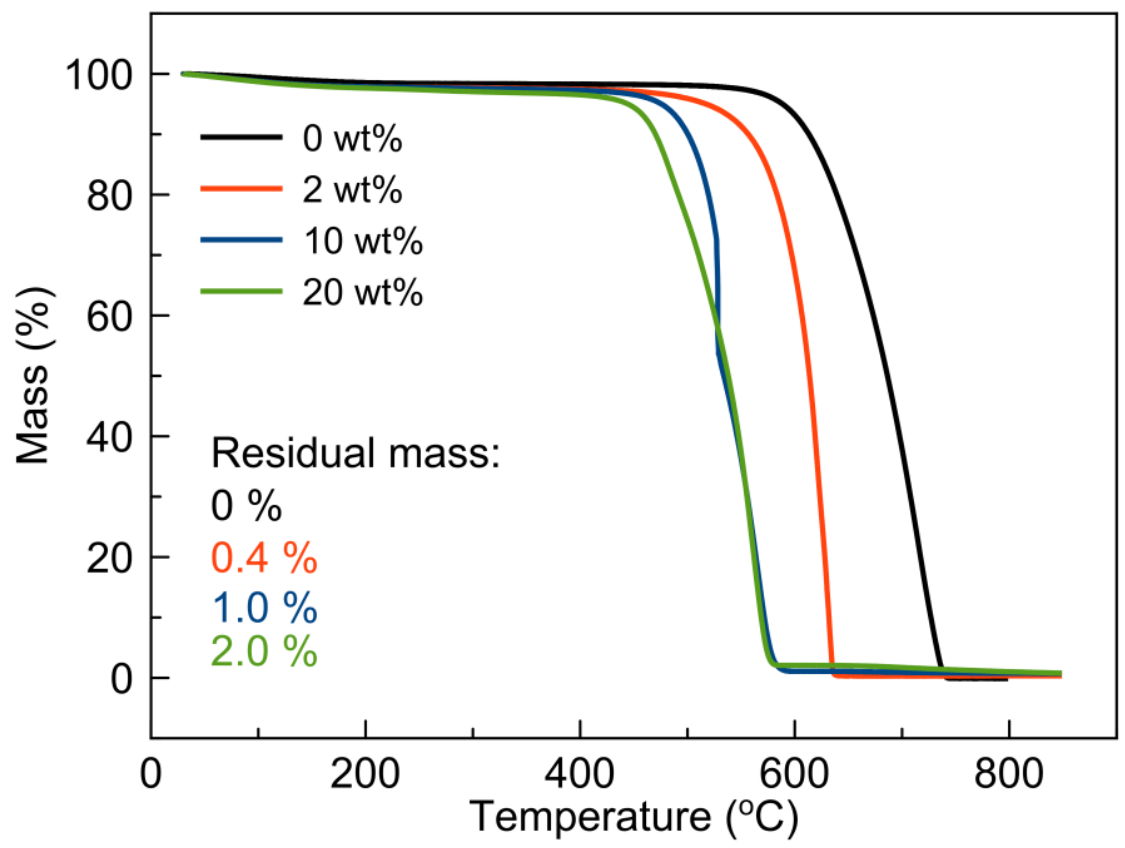

Figure S3. Thermogravimetric analysis of the $\mathrm{CN}_{\mathrm{x}}$ materials with different $\left\{\mathrm{Mo}_{3}\right\}$ cluster loadings in air. 

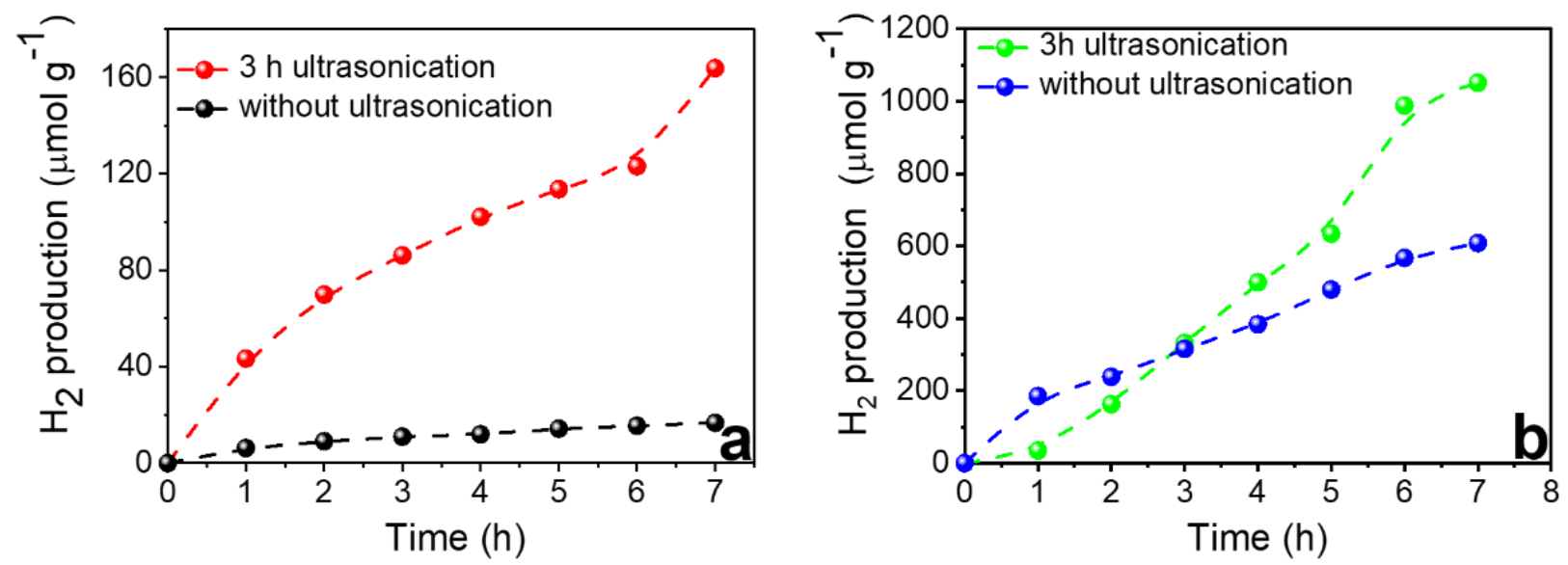

Figure S4. Effect of sonication on photocatalytic HER for (a) $\mathrm{CN}_{\mathrm{x}}$ and (b) $\mathrm{CN}_{\mathrm{x}}-\left\{\mathrm{Mo}_{3}\right\}$

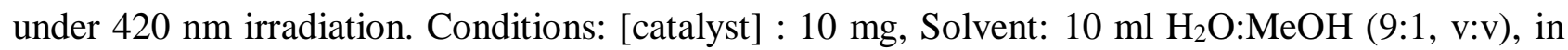
absence of any additional electron donors.

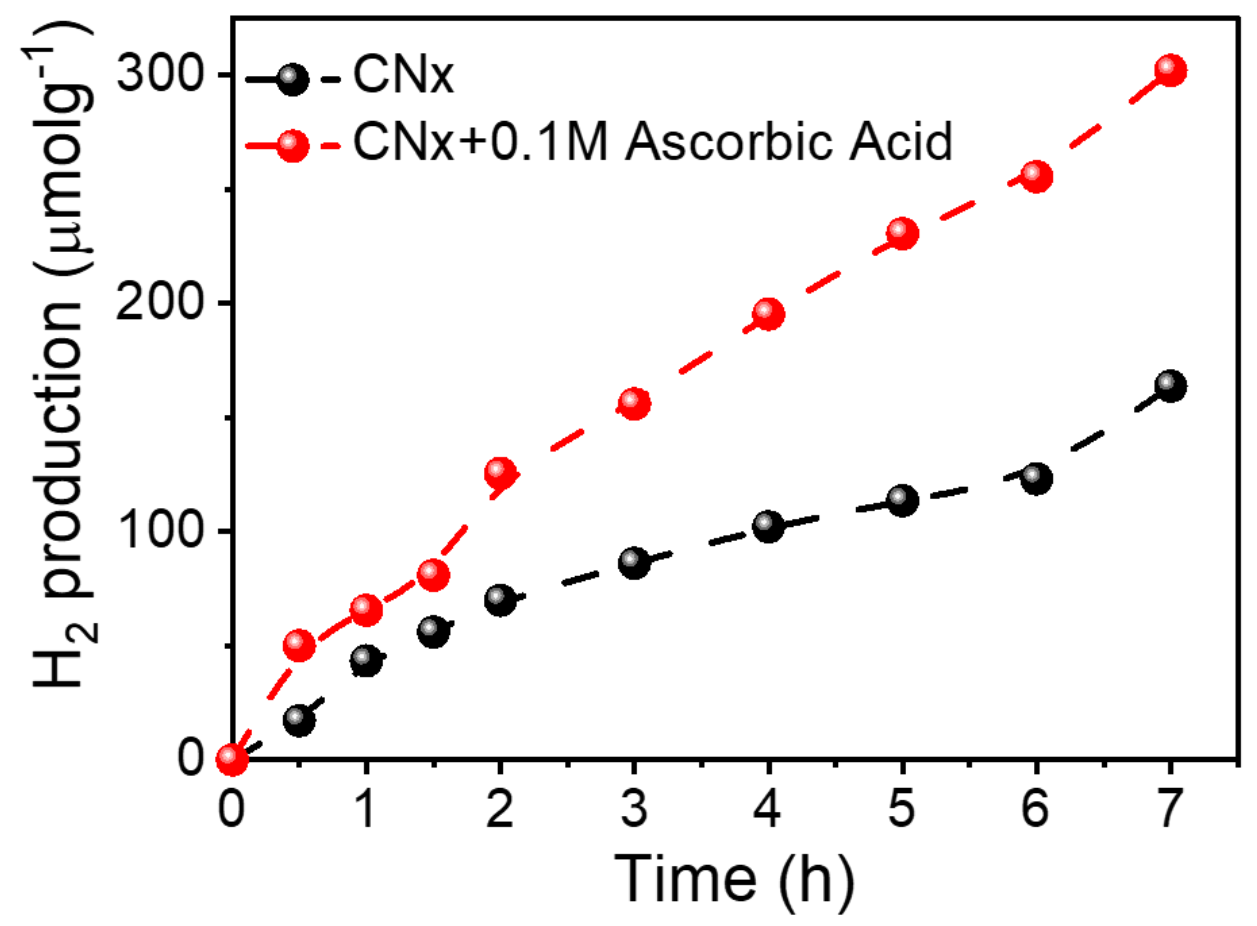

Figure S5. Effect of electron donor addition ( $0.1 \mathrm{M}$ ascorbic acid) on photocatalytic HER in presence of $\mathrm{CN}_{\mathrm{x}}$ under $420 \mathrm{~nm}$ irradiation. Conditions: [catalyst] : $10 \mathrm{mg}$, Solvent: $10 \mathrm{ml} \mathrm{H}{ }_{2} \mathrm{O}: \mathrm{MeOH}(9: 1$, $\mathrm{v}: \mathrm{v})$. 


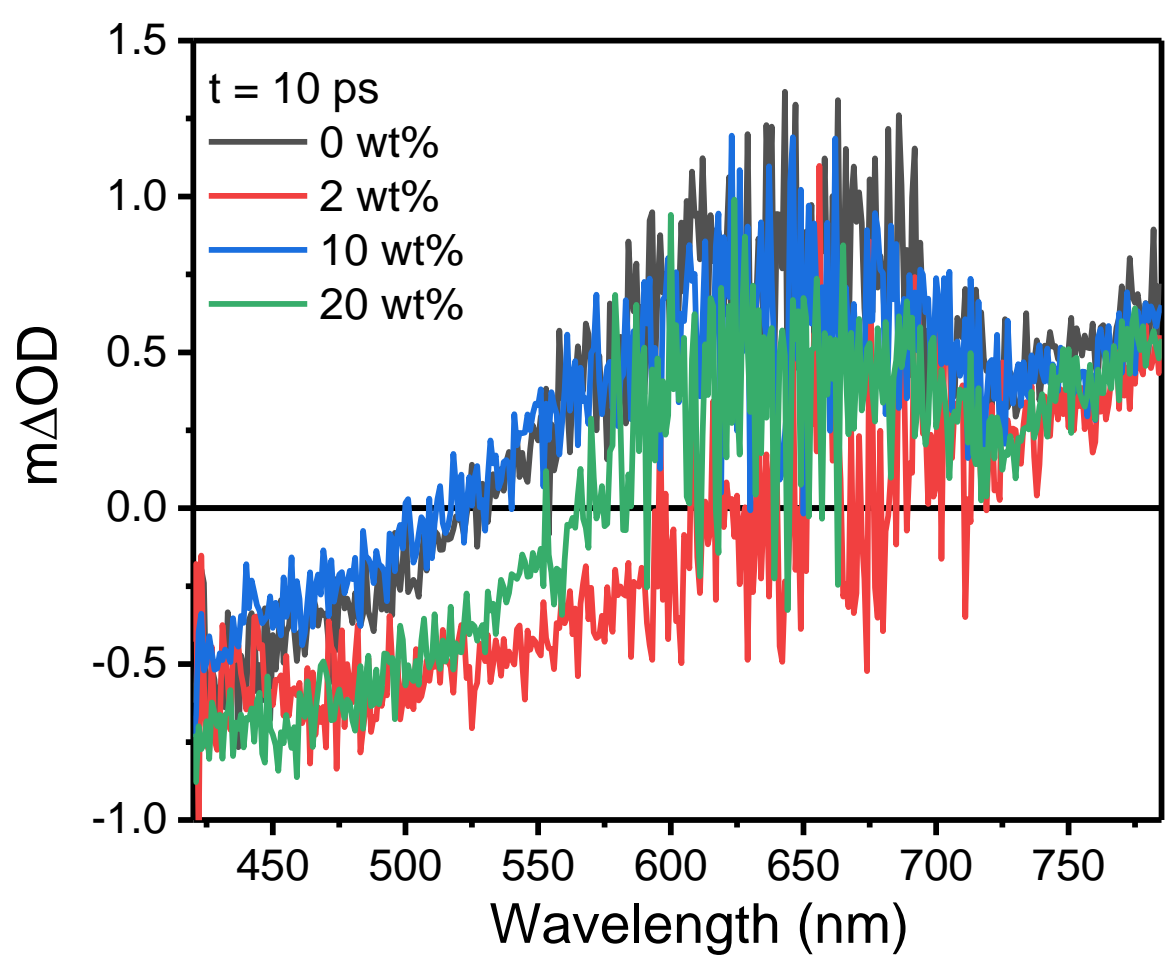

Figure S6. fs-TAS spectra of $\mathrm{CN}_{\mathrm{x}^{-}}\left\{\mathrm{Mo}_{3}\right\}$ dispersions in $\mathrm{H}_{2} \mathrm{O}$ upon excitation at $325 \mathrm{~nm}$ at 10 ps delay times. The figure displays the raw data. 

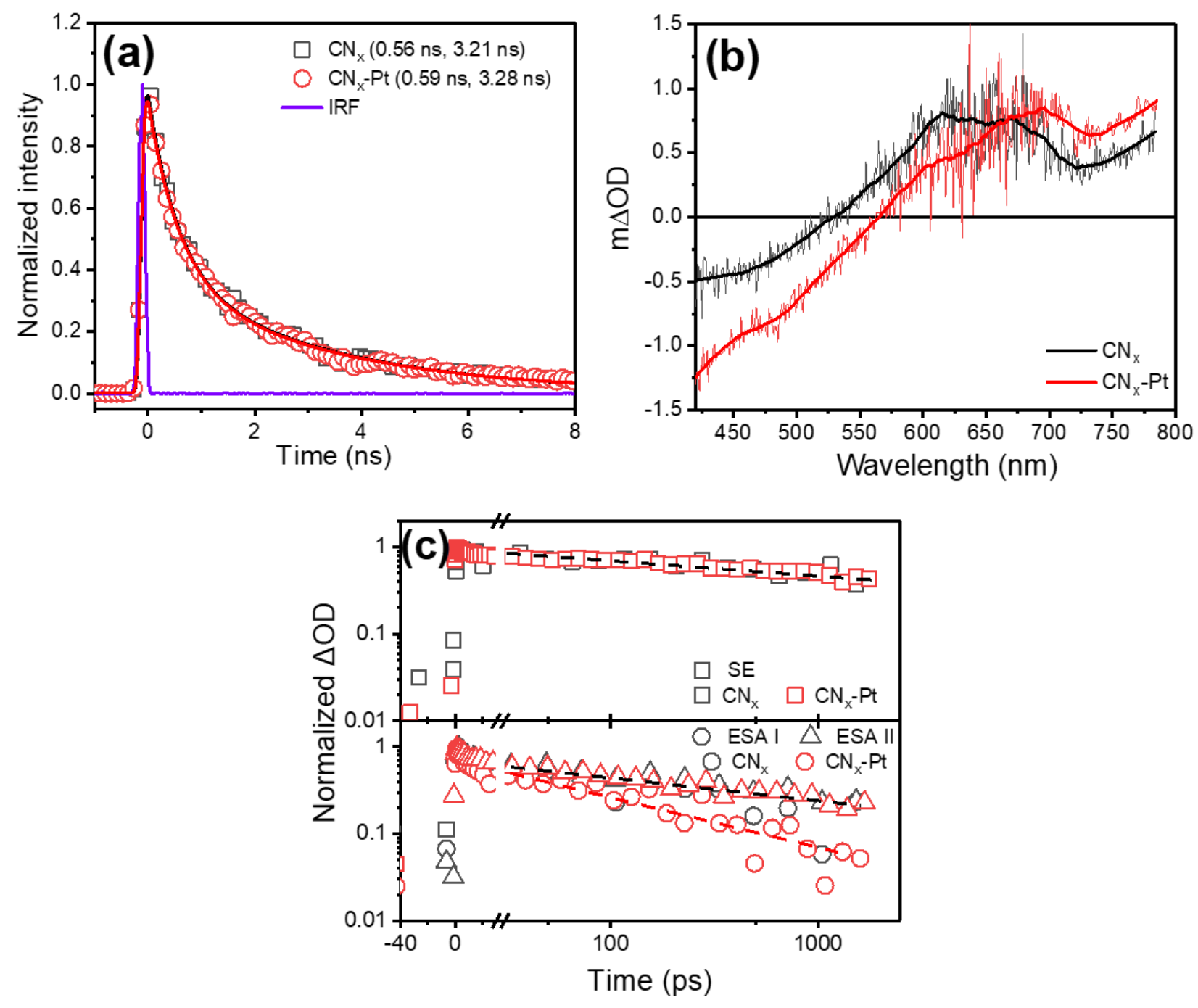

Figure S7. (a) Time-resolved photoluminescence decay curves of Pt functionalized $\mathrm{CN}_{\mathrm{x}}$ samples after $385 \mathrm{~nm}$ photoexcitation. The samples were prepared by drop casting. (b) fs-TAS spectra at 10 ps delay of $\mathrm{CN}_{\mathrm{x}}-\mathrm{Pt}$ dispersions in $\mathrm{H}_{2} \mathrm{O}$ upon excitation at $325 \mathrm{~nm}$ and corresponding (c) fs-TAS decay kinetics obtained by spectrally integrating the transient absorption data in different probe wavelength ranges. A quantitative analysis of the transient absorption data indicates, that the kinetics can be described by a power law model. The exponent of the power law is smaller than unity $(\sim 0.43)$, suggesting that trapping/detrapping plays a significant role in excited state dynamics of the $\mathrm{CN}_{\mathrm{x}}-\mathrm{Pt}$ samples. This is consistent with the comparably slow time scale for the recombination process. 


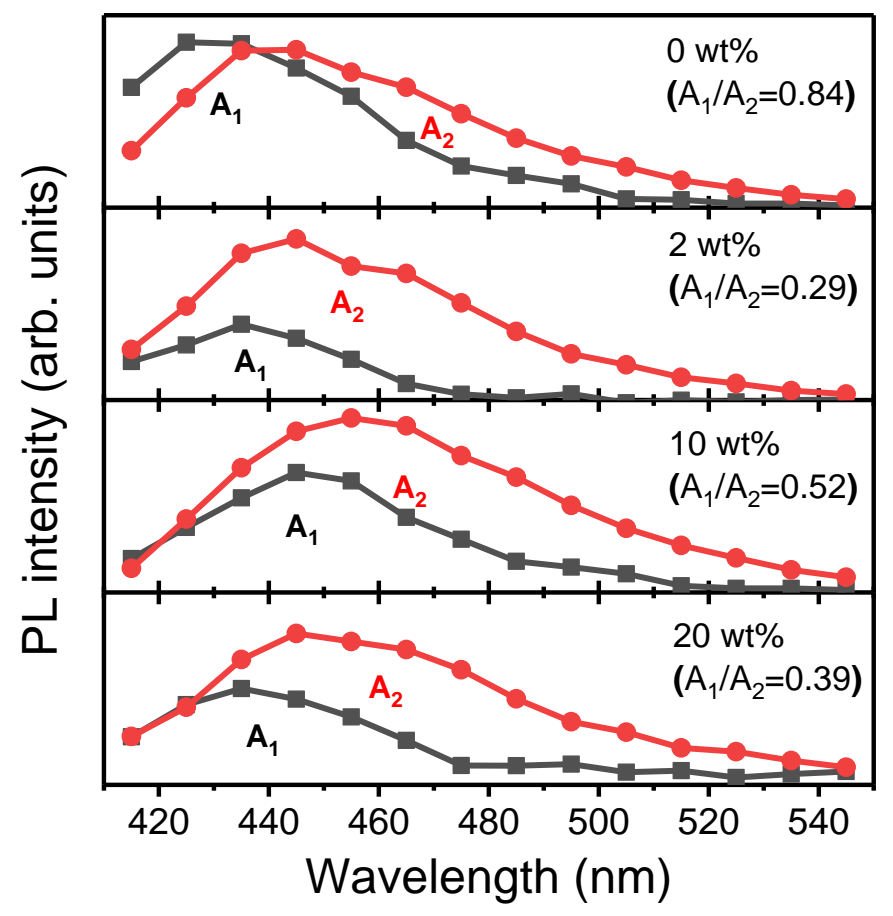

Figure S8. Species-associated emission spectra of $\mathrm{CN}_{x}-\left\{\mathrm{Mo}_{3}\right\}$ with respective lifetimes (black lines present emission from the short-lived photoluminescence $(\tau<1 \mathrm{~ns})$, while the red spectra reflect the spectra distribution of the long-lived emission with lifetimes ranging from 3.0 to $5.5 \mathrm{~ns}$ ). The lifetimes are obtained by a global fit of the two-dimensional streak camera data with a biexponential model. The experimental response function of the streak camera measurements is $0.06 \mathrm{~ns}$ wide.
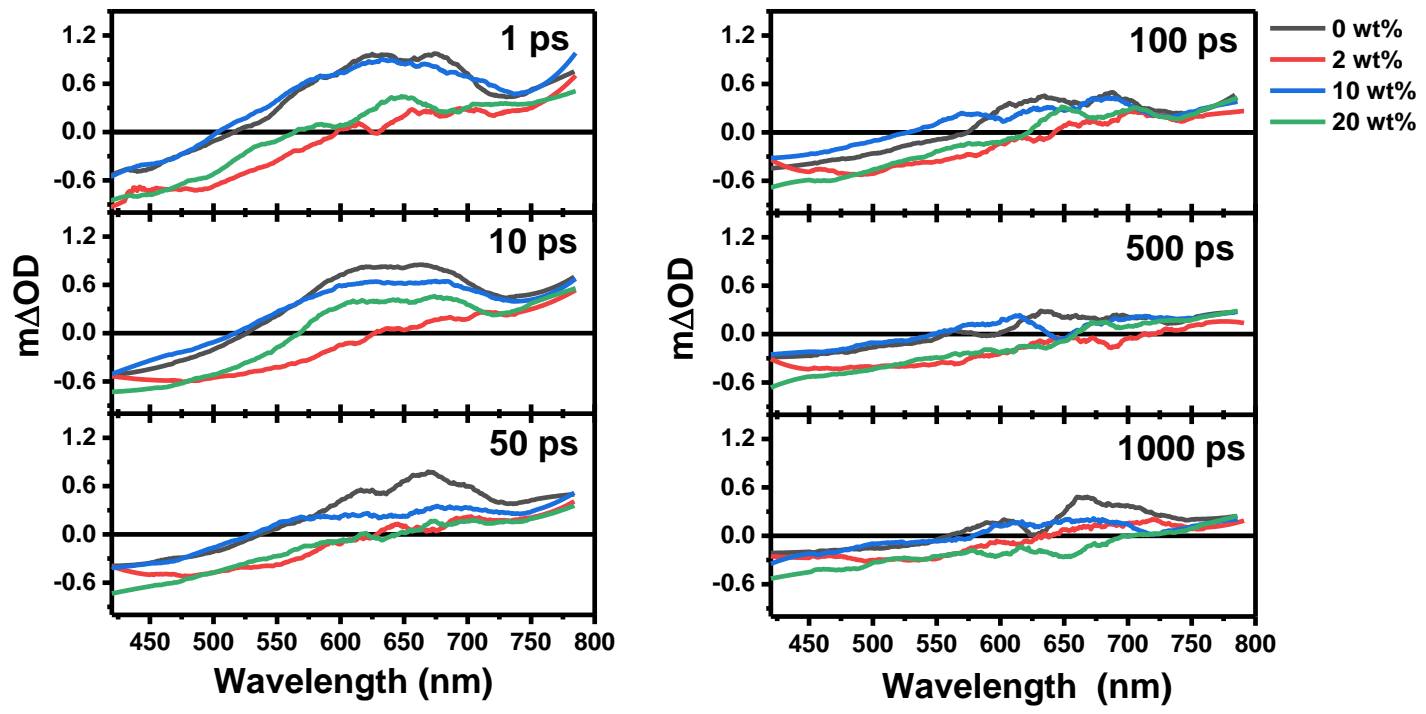

Figure S9. fs-TAS smoothed spectra of $\mathrm{CN}_{\mathrm{x}^{-}}\left\{\mathrm{Mo}_{3}\right\}$ dispersions in $\mathrm{H}_{2} \mathrm{O}$. The spectra were recorded upon $325 \mathrm{~nm}$ excitation at different delay times. 


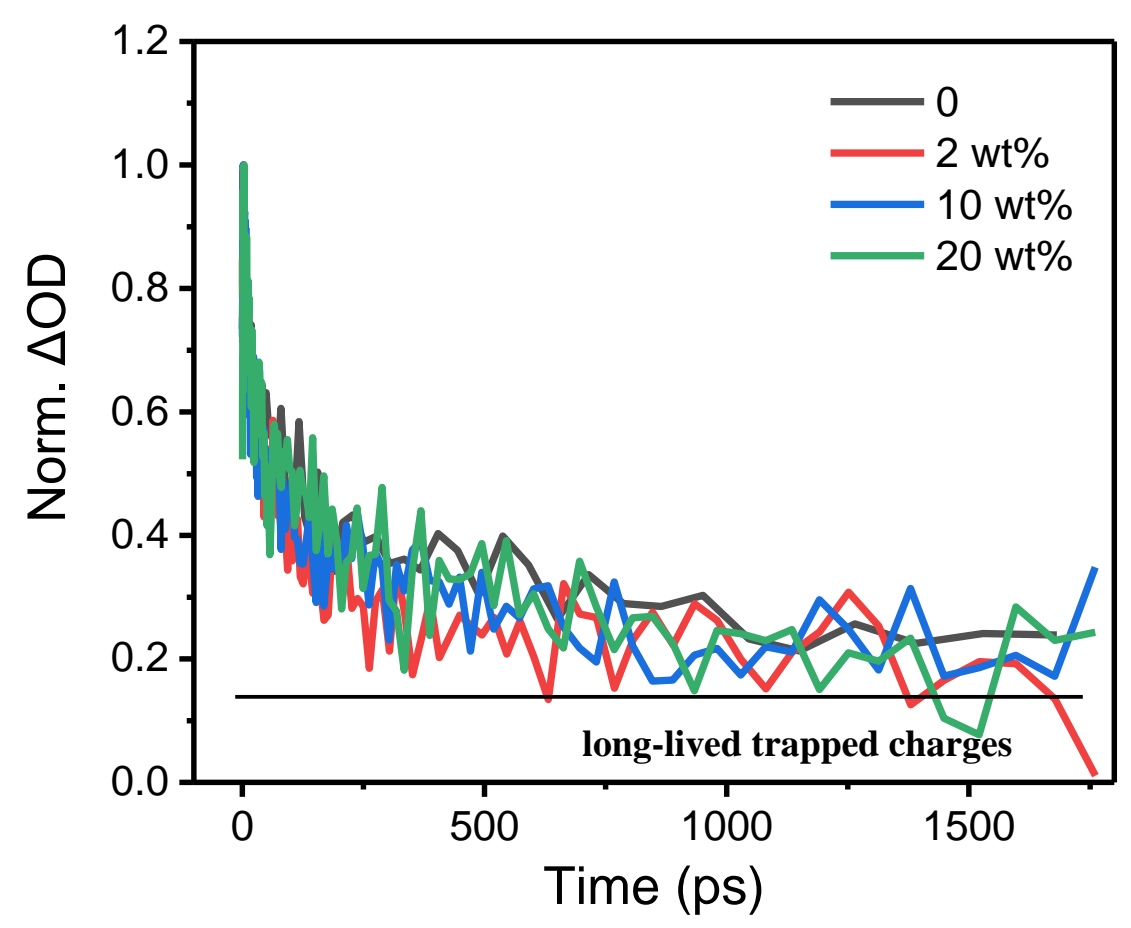

Figure S10. fs-TAS decay of $\mathrm{CN}_{\mathrm{x}^{-}}\left\{\mathrm{Mo}_{3}\right\}$ dispersions in $\mathrm{H}_{2} \mathrm{O}$ integrated within NIR regions upon 325 nm excitation.

\section{Theoretical calculations:}

Density Functional Theory (DFT) calculations were performed using the Vienna Ab initio Simulation Package (VASP) version 5.4.4 using the projector-augmented wave (PAW) method to represent the basis set. ${ }^{1-5}$ For accuracy of the electronic properties, the Heyd-Scuseria-Ernzerhof (HSE06) hybrid functional was employed. ${ }^{6,7}$ The screening parameter $m$ in HSE was set at $0.2 \AA^{-1}$ and the exchange parameter a was 0.25 . Grimme's D3 dispersion correction was used to describe long range dispersive interactions. ${ }^{8,9}$ The wavefunction was optimized to an accuracy of $10^{-6} \mathrm{eV}$ while geometries were relaxed until the forces reached below $5 \cdot 10^{-2} \mathrm{eV} \AA^{-1}$. Gaussian finite-temperature smearing was employed with a smearing width of $0.01 \mathrm{eV}$. A plane wave energy cut-off of $400 \mathrm{eV}$ for both $\left\{\mathrm{Mo}_{3}\right\}$ and $\mathrm{CN}_{\mathrm{x}}$. To offset the spurious interactions between the periodic images, vacuum was introduced along the z-direction $(\sim 20 \AA)$ for $\mathrm{CN}_{\mathrm{x}}$ and $\left\{\mathrm{Mo}_{3}\right\}$ was placed to the center of cubic vacuum box (40 $\AA$ ) with dipole corrections. Integration in the reciprocal space was performed on a $5 \times 5 \times 1$ Monkhorst-Pack $\boldsymbol{k}$-grid mesh. For implicit solvation effects in water, the GLSSA13 solvent model implemented in the VASPsol extension was invoked, ${ }^{10-12}$ using a dielectric constant of bulk water at room temperature of 78.4 . 

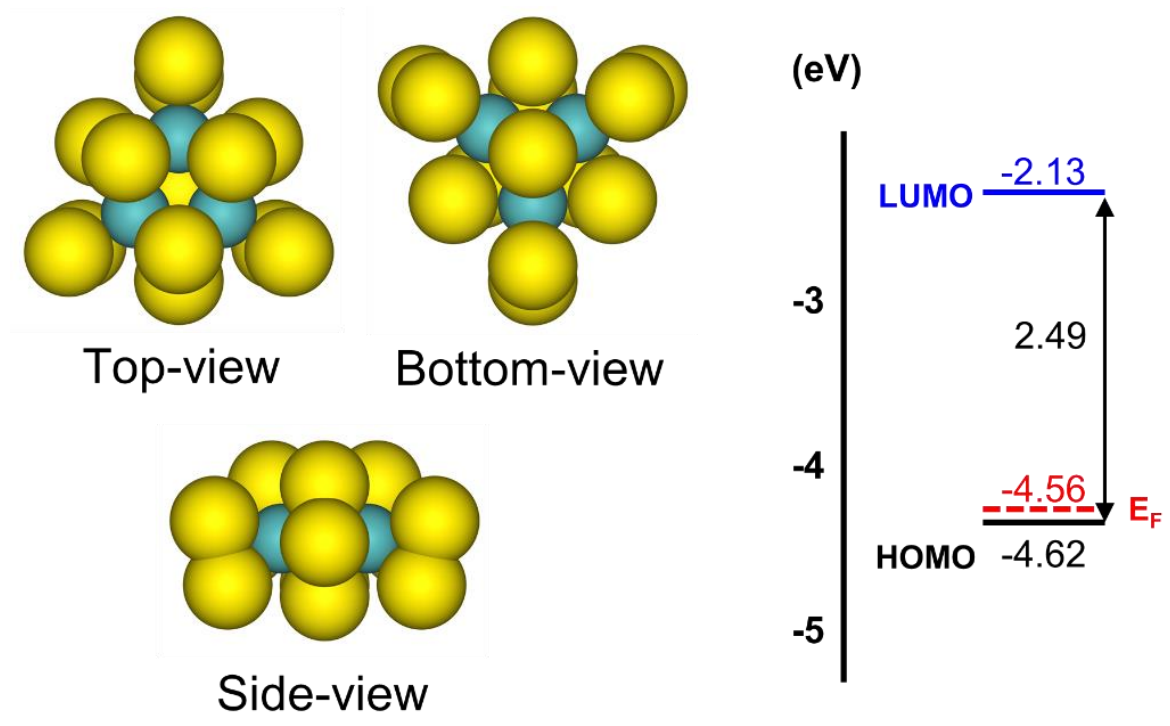

Figure S11. Scheme of the structure $\left\{\mathrm{Mo}_{3}\right\}$ employed in DFT calculation and HOMO-LUMO energy.

\section{References}

1. G. Kresse, J. Hafner, Phys. Rev. B 1993, 47, 558-561.

2. G. Kresse, J. Hafner, Phys. Rev. B 1994, 49, 14251-14269.

3. G. Kresse, J Furthmüller, Comput. Mater. Sci. 1996, 6, 15-50.

4. G. Kresse, J. Furthmüller, Phys. Rev. B 1996, 54, 11169-11186.

5. G. Kresse, D. Joubert, Phys. Rev. B 1999, 59, 1758-1775.

6. Heyd, J.; Scuseria, G. E.; Ernzerhof, M. J. Chem. Phys. 2003, 118, 8207-8215.

7. Heyd, J.; Scuseria, G. E.; Ernzerhof, M. Erratum: Hybrid Functionals Based on a Screened Coulomb Potential [J. Chem. Phys. 118, 8207 (2003)]. J. Chem. Phys. 2006, 124, 219906.

8. S. Grimme, J. Antony, S. Ehrlich, and S. Krieg, J. Chem. Phys. 2010, 132, 154104.

9. Grimme, S. Ehrlich, and L. Goerigk, J. Comp. Chem. 2011, 32, 1456.

10. D. Gunceler, K. Letchworth-Weaver, R. Sundararaman, K. A. Schwarz, T. A. Arias, Model. Simul. Mater. Sci. Eng. 2013, 21, 074005.

11. K. Mathew, R. G. Hennig, ArXiv160103346 Cond-Mat 2016.

12. K. Mathew, R. Sundararaman, K. Letchworth-Weaver, T. A. Arias, R. G. Hennig, J. Chem. Phys. 2014, 140, 084106. 